FACULTY OF ECONOMICS AND APPLIED ECONOMIC SCIENCES

CENTER FOR ECONOMIC STUDIES

ENERGY, TRANSPORT \& ENVIRONMENT

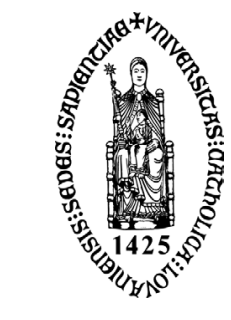

KATHOLIEKE UNIVERSITEIT LEUVEN

WORKING PAPER SERIES

$n^{\circ}$ 2003-9

\title{
CONGESTION AND TAX COMPETITION IN A PARALLEL NETWORK
}

\author{
B.De Borger (University of Antwerp) \\ S.Proost (K.U.Leuven) \\ K.Van Dender (University of California at Irvine)
}

August 2003

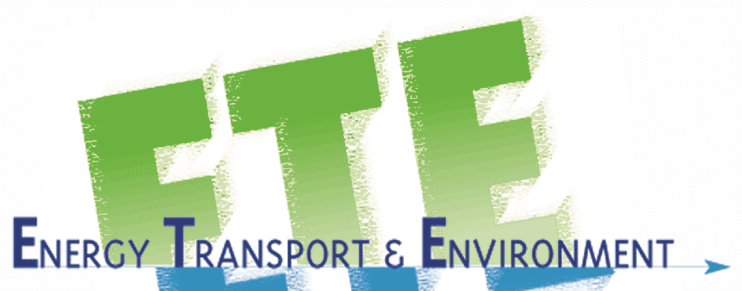

secretariat:

Isabelle Benoit

KULeuven-CES

Naamsestraat 69, B-3000 Leuven (Belgium)

tel: $\quad+32(0) 1632.66 .33$

fax: $\quad+32(0) 1632.69 .10$

e-mail: Isabelle.Benoit@econ.kuleuven.ac.be http://www.kuleuven.be/ete 


\title{
Congestion and tax competition in a parallel network
}

By

\author{
B.De Borger ${ }^{*}$, S.Proost ${ }^{* *}$, K.Van Dender ${ }^{* * *}$
}

\begin{abstract}
$\underline{\text { Abstract }}$
The purpose of this paper is to study tax competition on a parallel road network when different governments have tolling authority on the different links of the network. Reflecting many current situations in Europe, each link is used by both local and transit traffic; moreover, transit has a choice of route. Each government maximises the surplus of local users plus total tax revenues in controlling local and transit transport. Three types of tolling systems are considered: (i) toll discrimination between local traffic and transit, (ii) uniform tolls on local and transit transport, (iii) local tolls only. The results suggest that the welfare effects of introducing transit tolls are large, but that differentiation of tolls between local and transit transport as compared to uniform tolls does not yield large welfare differences. It is also found that the welfare effects of coordination between countries are relatively small in comparison with the welfare gains of tolling transit. The numerical model further illustrates the effects of different transit shares and explicitly considers the role of asymmetries between countries. Higher transit shares strongly raise the Nash equilibrium transit toll and slightly decrease local tolls. With asymmetric demands, the welfare gains of introducing differentiated tolling rise strongly for the country with lower local demand.
\end{abstract}

Keywords: congestion pricing, transit traffic

JEL: H23, H71, R41, R48

\footnotetext{
* Department of Economics, University of Antwerp, Prinsstraat 13, B-2000 Antwerp, Belgium (bruno.deborger@ua.ac.be)

** Department of Economics, Catholic University of Leuven, Naamsestraat 69, B-3000 Leuven, Belgium (stef.proost@econ.kuleuven.ac.be) and visiting fellow CORE, Voie du Roman Pays, 34, B-1348 LLN; Belgium

*** Department of Economics, University of California at Irvine, Irvine, CA 92697-5100 (kvandend@uci.edu)
} 


\section{Introduction}

Countries' road networks are usually publicly provided, they are congestible, and they are accessible to local and to transit users. Moreover, in many cases transit users have a choice between different jurisdictions' road networks. For example, there are two main routes from South-Central Europe (Switzerland, Austria, Italy) to the north (Belgium, Netherlands, Denmark, etc.), one through France, the other via Germany. Alternatively, consider the transalpine crossing between Germany and Italy, where Austria and Switzerland compete for transit traffic. In both examples, transit has a choice of routes and it interacts with local traffic in each country.

In these circumstances, how would a local jurisdiction like to price access to its infrastructure ${ }^{1}$ In this paper we study this question under various assumptions on the type of allowable tolls, for given levels of infrastructure supply. More specifically, we look at a model with two parallel routes that are operated by two countries. Local traffic and transit traffic both contribute to congestion, and the two countries compete for revenue from transit. Assuming that countries maximise a welfare function consisting of local consumer surplus and tax revenues from local and transit traffic, we study strategic tolling by individual countries under various tolling schemes. First, we assume that local traffic and transit can be separately tolled. Second, we look at the case where only uniform tolls are possible or acceptable. Third, we consider the case where only local traffic can be tolled.

Despite the highly stylised setting, the examples referred to above show that the model does capture the main ingredients of a number of situations in Europe (North-South axe, transalpine crossing, etc.). The analysis of this paper then describes the potential tax competition between countries in controlling local and transit transport. Moreover, in view of recent innovations in transport taxation within the EU, all three types of tolling

\footnotetext{
${ }^{1}$ Although the discussion is set in the context of congestible road infrastructure in two countries, similar issues arise in the public provision of e.g. health, educational and recreational services. In this sense, the ideas studied in this paper are not limited to the transport sector. The key feature of the analysis is that foreign (transit) users are not restricted to a particular jurisdiction but can choose between several, and that jurisdictions compete for revenue from transit.
} 
regimes considered are highly policy-relevant. New forms of transport pricing instruments include kilometre charges (implemented in Germany as of early 2003), tolls (already existing, among others, on French motorways), and cordon pricing (London). More sophisticated time-of-day pricing regimes are under consideration. The case of differentiated tolls is relevant because, as long as Member States use different tolling instruments, the implied local and transit tax levels will almost automatically differ. Alternatively, the case of uniform tolls provides an appropriate description when EU member countries use the same pricing instruments, because explicit toll discrimination between local and transit transport contradicts EU regulations. Finally, the case of 'local tolls only' is likely to remain extremely important. It resembles the current situation in many countries, where fuel taxes are the main tolling instrument. High fuel taxes can easily be evaded by transit transport, especially in relatively small countries, so that the exclusive use of fuel taxes is similar to tolling local traffic only. It is likely that several countries will be limited to tolling local traffic for quite some time, if only because of the technical difficulties and implementation costs associated with tolling transit.

With this background in mind, this paper studies the welfare implications of tax competition on a parallel network with local and transit traffic, where the latter is assumed to have a choice of route. The analysis builds upon several strands of the recent literature. First, the large literature on the optimal pricing of road use in the presence of congestion has recently been extended to optimal tolling on simple parallel networks. For example, Braid (1996) and Liu and McDonald (1998) consider models with homogeneous users to study optimal second-best tolls on one link in the network, assuming that other links can not be optimally tolled for technical or political reasons. They suggest that the optimal second-best tolls on one link tend to be low, and could actually be negative. Moreover, the welfare gains from this type of second-best tolls are found to be low. However, more recent research by Small and Yan (2001) and Verhoef and Small (2003) shows that allowing for a heterogeneous population of road users substantially increases the benefits from second best tolls.

Second, a small but growing literature does explicitly study the role of different ownership regimes in models with parallel routes. For example, Verhoef et al. (1996) 
consider competition between a private road and a free-access road, and compare the second-best optimal tolls with those obtained when both roads are privately owned. De Palma and Lindsay (2000) use a bottleneck model of congestion and compare three types of ownership structure: a private road competing with a free access road, two competing private roads, and competition between a private and a public operator. Note, however, that these papers do not incorporate both transit and local traffic demand and, therefore, do not deal with tax competition for transit by welfare maximising governments.

Third, a few recent studies have looked specifically at tax exporting in the transport sector, within a serial network setting. Levinson (2001) analyses US States' choice of instruments for financing transportation infrastructure. Theory predicts, and an econometric analysis confirms, that jurisdictions are more likely to opt for toll-financing instead of e.g. fuel taxes, when the share of non-residential users is large. Tolls become more attractive because they allow price discrimination and tax-exporting. De Borger et al (2003) apply a large-scale numerical optimisation model to study tax exporting behaviour by individual regions in a model with both domestic and international freight transport. However, these models are based on a different network structure, they do not consider transit route choice, and they do not study the properties of reaction functions and the resulting Nash equilibria. Moreover, they do not look at the broad variety of tax instruments dealt with in the current paper.

Finally, in a slightly broader sense, the welfare evaluation of transport tax competition of this paper also complements the few explicit numerical illustrations of the welfare effects of various types of tax competition ${ }^{2}$. An early example is Wildasin (1989), who finds substantial welfare effects of property tax competition in the US. More recently, Sorensen (2000) estimates the welfare loss of tax harmonisation within the EU at less than $1 \%$ of GDP. The welfare losses of capital tax competition have also been estimated to be relatively small under some, but not all, scenarios considered (Parry (2003)). Finally, Sinn (2003) discusses various forms of 'systems competition', referring in

\footnotetext{
${ }^{2}$ Seminal contributions to the tax competition literature include Arnott and Grieson (1981), Mintz and Tulkens (1986), and Kanbur and Keen (1993). For a recent survey, see Wilson (1999).
} 
general to competition between countries for mobile factors, e.g. within the EU, or on a global scale. He finds the welfare effects to be detrimental in some, but not all, cases.

The contributions of this paper can be summarized as follows. At the theoretical level, it fills two gaps in the literature. First, although competition between operators has been considered before (see the references given above), a common feature of this work is the absence of transit users that can choose between routes. In contrast, our analysis incorporates route choice for transit, and it focuses on the interaction between local and transit traffic when governments compete for revenue from transit. The distinction between local and transit traffic also allows us to explicitly consider a wider range of tolling instruments compared to the existing literature. Importantly, it allows us to look at the implications of pricing only part of the users (local traffic only), a case that seems especially policy-relevant for the near future within the EU. Second, our analysis focuses on competition in a parallel network between two local welfare-maximising governments. This type of competition seems highly relevant in the context of European transport policy and has not been studied in detail in the literature.

Finally, complementing the theoretical analysis by a stylised numerical illustration allows us to pin down orders of magnitude for each of the issues analysed. It allows us to shed some light on the welfare effects of introducing various types of tolling instruments, the benefits of toll harmonisation, etc. Moreover, the sensitivity of the results to transit shares, to congestion differences and to demand asymmetries can easily be evaluated. Among others, the numerical results suggest that despite a substantial amount of tax exporting, the efficiency costs of tax exporting are fairly small under most scenarios, confirming recent results obtained by Parry (2003) in a totally different context. Also, the welfare effects of uniform versus differentiated tolls are quite limited. To the contrary, using local tolls only is quite costly in welfare terms.

The structure of the paper is as follows. Section 2 presents the general theoretical model. We specify the characteristics of the network and derive optimal tax rules for a given country (implicitly defining the country's reaction functions) for various types of tolling instruments. In Section 3 we simplify by assuming linear demand and cost functions; this allows us to explicitly analyse the properties of the reaction functions, as 
well as the resulting Nash equilibria. Section 4 reports on a numerical illustration. Seven equilibria are numerically evaluated: the no-toll equilibrium, Nash with differentiated tolls, Nash with uniform tolls, Nash with local tolls only, a centralised solution with differentiated tolls, a centralised solution with local tolls only and, finally, a scenario with collusion between the countries. The role of the share of transit and of demand and congestion asymmetries between countries is evaluated. Section 5 concludes.

\section{The theoretical model}

In this section we first present the structure of the model and provide an overview of the tolling systems analysed. We then study the optimal behaviour of an individual country for each of the cases considered. Throughout this section we focus on the economically most interesting results; most of the derivations are relegated to appendices.

\subsection{Structure of the model and the pricing schemes considered}

We consider the simplest possible setup. The network analysed is depicted in Figure 1. It consists of two parallel links, and it is assumed that pricing of each link is the responsibility of a different government. Each link carries local traffic, which cannot change routes, and transit traffic, which can. Link capacities are given and both links are congestible.

Both governments are assumed to maximise a welfare function that reflects two concerns, viz. (i) the travel conditions of its local users and the associated welfare, and (ii) total tax revenues on the link it controls. We assume that all traffic flows are uniformly distributed over time and are equal in both directions, allowing us to focus on one representative unit period and one direction. 
Figure 1 The network

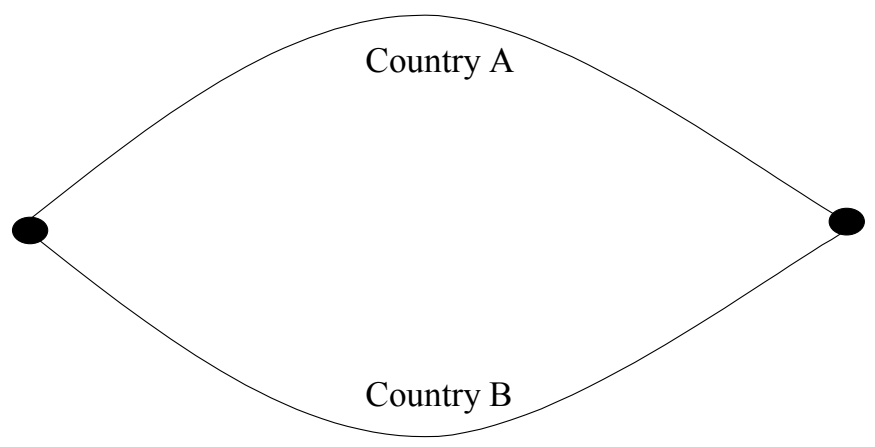

The combinations of tolling instruments as well as the notation used are summarised in Table 1. Note that differentiated tolls for local and transit demand may seem unrealistic because it runs against the non-discrimination rules in trade agreements. However, by choosing a particular toll structure, countries are able to implicitly price-discriminate against foreign users ${ }^{3}$. Importantly, note that Table 1 only lists the three cases where both countries use the same type of tolling ${ }^{4}$. In order not to lengthen the paper substantially, we deliberately limit the scope of the analysis to these three cases. However, extension to the mixed cases is both conceptually and analytically straightforward.

\footnotetext{
${ }^{3}$ Take as an example the yearly lump-sum fee for access to a country's network that is to be paid in Switzerland and in many other countries (the Eurovignette system): this in fact boils down to discrimination in favour of the local users as, almost by definition, they use the network more frequently.

${ }^{4}$ In principle, we could also examine cases where the governments use different types of tolling systems. Indeed, these mixed cases exist in reality: France uses a uniform tolling system for motorways while Germany has no explicit toll, so uses a system similar to the case where only local traffic can be tolled.
} 
Table 1: The tolling systems studied

\begin{tabular}{|l|l|l|}
\hline $\begin{array}{l}\text { Description of tolling systems } \\
\text { studied }\end{array}$ & Tolling instruments & Example of practical relevance \\
\hline $\begin{array}{l}\text { Differentiated tolls for local and } \\
\text { transit transport }\end{array}$ & $\begin{array}{l}\tau_{i}: \text { transit toll region i } \\
(\mathrm{i}=\mathrm{A}, \mathrm{B}) \\
t_{i}: \text { toll on local transport in } \\
\text { region } \mathrm{i}(\mathrm{i}=\mathrm{A}, \mathrm{B})\end{array}$ & $\begin{array}{l}\text { Eurovignette (favors more intensive } \\
\text { local users) }\end{array}$ \\
\hline $\begin{array}{l}\text { Uniform tolls for local and transit } \\
\text { transport }\end{array}$ & $\begin{array}{l}\theta_{i}: \text { uniform toll in region i } \\
(\mathrm{i}=\mathrm{A}, \mathrm{B})\end{array}$ & Current tolls on French highways \\
\hline $\begin{array}{l}\text { Tolls on local users only, no transit } \\
\text { toll }\end{array}$ & $\begin{array}{l}t_{i}: \text { toll on local transport in } \\
\text { region i (i=A,B) }\end{array}$ & Fuel taxes, parking charges \\
\hline
\end{tabular}

Turning to the specification of the model, demand for local transport in A and B is represented by the strictly downward sloping inverse demand functions $P_{A}^{Y}\left(Y_{A}\right)$ and $P_{B}^{Y}\left(Y_{B}\right)$, respectively, where $Y_{A}$ and $Y_{B}$ are the local flows on both links. The generalised prices $P_{i}^{j}($.$) include resource costs, time costs and tax payments or user charges.$ Similarly, overall demand for transit traffic is described by the strictly downward sloping inverse demand function $P^{X}(X)$, where $X$ is the total transit traffic flow. We have

$$
X_{A}+X_{B}=X
$$

where $X_{A}$ and $X_{B}$ are the transit flows via A and B, respectively. The two links are assumed to be perfect substitutes: transit users choose the route with the lowest generalised (money plus time) cost but have no specific preferences towards any of the routes.

Turning to the cost side, the generalised user cost for transit via route $A$, denoted $g_{A}^{X}$, equals the sum of the time and resource costs of travel plus the transit toll on $A^{5}$ :

$$
g_{A}^{X}=C_{A}\left(X_{A}+Y_{A}\right)+\tau_{A}
$$

\footnotetext{
${ }^{5}$ In what follows, we develop all specifications for the case of differentiated tolling; the cases of uniform tolls and local tolls only are easily derived by analogy.
} 
In this expression, $C_{A}($.$) is the time plus resource cost on route A$, assumed to be strictly increasing in the total traffic volume. Similarly, the generalised user cost for local use of route $A$ is given by

$$
g_{A}^{Y}=C_{A}\left(X_{A}+Y_{A}\right)+t_{A} .
$$

User costs for route B are defined in an analogous way.

Since we assume perfect substitutability between links for transit, in equilibrium the generalised cost for transit equals the generalised cost on the link with the lowest generalised cost. If both routes are used, transit traffic will be distributed across links so as to equalise generalised costs. Specifically, the Wardrop principle implies that

$$
\begin{aligned}
& P^{X}(X)=g_{A}^{X}=C_{A}\left(X_{A}+Y_{A}\right)+\tau_{A} \text { iff } X_{A}>0 \\
& P^{X}(X)=g_{B}^{X}=C_{B}\left(X_{B}+Y_{B}\right)+\tau_{B} \text { iff } X_{B}>0
\end{aligned}
$$

Moreover, equilibrium for local traffic implies

$$
\begin{aligned}
& P_{A}^{Y}\left(Y_{A}\right)=g_{A}^{Y}=C_{A}\left(X_{A}+Y_{A}\right)+t_{A} \\
& P_{B}^{Y}\left(Y_{B}\right)=g_{B}^{Y}=C_{B}\left(X_{B}+Y_{B}\right)+t_{B}
\end{aligned}
$$

Unless otherwise noted, we focus on the case where all types of traffic exist in equilibrium, i.e., there is local and at least some transit in both countries. In theory, of course, this is just one of the many (in fact, sixteen) possibilities that exist. Indeed, when certain taxes are too high or there is too much other traffic using the same road, some types of transport demand may disappear, affecting the structure of the remaining demand functions. This is a well-known problem in the tax competition literature (see Mintz and Tulkens, 1986). However, many of these cases are not very interesting in practice (e.g., cases where there is no local traffic, cases where there is no transit in neither A or B). We therefore largely focus on the most relevant case where both types of transport exist in both countries.

\subsection{Optimal tolls in a parallel network: the case of differentiated tolls}

Assume each country can set different tolls on local transport and on transit on its territory. To study the optimal tolls set by, say, country A, we use the properties of the 
reduced-form demand system for the different types of transport in the first-order conditions for welfare optimisation in country A.

The reduced-form demand system is obtained by solving the equilibrium conditions (2), (3) and (4); it expresses local and transit demand in both countries as a function of all tax rates.:

$$
\begin{aligned}
& X_{A}^{r}\left[\tau_{A}, t_{A}, \tau_{B}, t_{B}\right] \\
& X_{B}^{r}\left[\tau_{A}, t_{A}, \tau_{B}, t_{B}\right] \\
& Y_{A}^{r}\left[\tau_{A}, t_{A}, \tau_{B}, t_{B}\right] \\
& Y_{B}^{r}\left[\tau_{A}, t_{A}, \tau_{B}, t_{B}\right]
\end{aligned}
$$

In Appendix 1 we show that these demand functions have the following properties:

$$
\begin{aligned}
& \frac{\partial X_{A}^{r}}{\partial \tau_{A}}<0, \frac{\partial X_{A}^{r}}{\partial \tau_{B}}>0 \frac{\partial X_{A}^{r}}{\partial t_{A}}>0, \frac{\partial X_{A}^{r}}{\partial t_{B}}<0 \\
& \frac{\partial Y_{A}^{r}}{\partial \tau_{A}}>0, \frac{\partial Y_{A}^{r}}{\partial \tau_{B}}<0 \frac{\partial Y_{A}^{r}}{\partial t_{A}}<0, \frac{\partial Y_{A}^{r}}{\partial t_{B}}>0 \\
& \frac{\partial X_{B}^{r}}{\partial \tau_{B}}<0, \frac{\partial X_{B}^{r}}{\partial \tau_{A}}>0 \frac{\partial X_{B}^{r}}{\partial t_{B}}>0, \frac{\partial X_{B}^{r}}{\partial t_{A}}<0 \\
& \frac{\partial Y_{B}^{r}}{\partial \tau_{B}}>0, \frac{\partial Y_{B}^{r}}{\partial \tau_{A}}<0 \frac{\partial Y_{B}^{r}}{\partial t_{B}}<0, \frac{\partial Y_{B}^{r}}{\partial t_{A}}>0
\end{aligned}
$$

Increasing local transport taxes in a given country raises demand and reduces transit; it raises transit and reduces local demand abroad. Higher transit taxes in a country have the opposite effects. The intuition is easy, realising that any tax change has two effects: first, it affects the distribution of transit over the two routes and, second, by affecting congestion levels in the two regions, it has an impact on the competition in each country between transit traffic and local traffic for the same road space. An example helps to illustrate this. Take the effect of increasing the transit tax in $B\left(\tau_{B}\right)$. This tax increase will make route $B$ less interesting for transit traffic so that $X_{B}$ goes down, whereas demand for transit on route A rises. However, there are secondary effects. The positive effect on $X_{A}$ raises congestion in $A$ and hence the generalised user cost, whereas the lower volume of transit on route $B$ decreases the generalised cost of using route $B$. The changes in 
congestion mitigate the initial transit effects described before; more importantly, they raises the demand for local traffic in country $\mathrm{B}$ and reduce demand for local transport $Y_{A}$.

Finally, in Appendix 1 we also show the following useful result on the relative impact of a transit tax and a tax on local transport on the demand for transit:

$$
\left|\frac{\partial X_{A}^{r}}{\partial \tau_{A}}\right|>\left|\frac{\partial X_{A}^{r}}{\partial t_{A}}\right|
$$

Both taxes have opposite effects, but in absolute value the transit tax has a larger effect on transit demand than an increase in the tax on local traffic. This makes intuitive sense because a higher local tax only affects transit demand indirectly via the induced reduction in congestion. This finding will be useful for the interpretation later.

Using the reduced-form demand system, we then proceed to analyse the optimal behaviour of a given country, conditional on the tolls set abroad. We assume that the appropriate welfare function used by each of the governments consists of the sum of consumer surplus for the local users plus the total tax revenues earned on local and transit traffic on its territory. Consumer surplus for foreigners is assumed to be ignored. Consider, therefore, the problem of country $A$ :

$$
\operatorname{Max}_{t_{A}, \tau_{A}} W_{A}=\int_{0}^{Y_{A}}\left(P_{A}^{Y}\left(Y_{A}\right)\right) d Y_{A}-g_{A}^{Y} Y_{A}+t_{A} Y_{A}+\tau_{A} X_{A},
$$

where, see before, $g_{A}^{Y}=C_{A}\left(X_{A}+Y_{A}\right)+t_{A}$, and the reduced-form demands for $X_{A}$ and $Y_{A}$ depend on all four tax rates, see (5). Moreover, the country takes the tolls $t_{B}, \tau_{B}$ in country $B$ as given.

The first-order conditions for an interior solution to (8) can be written:

$$
\begin{aligned}
& \left(t_{A}-Y_{A} \frac{\partial C_{A}}{\partial V_{A}}\right) \frac{\partial Y_{A}^{r}}{\partial t_{A}}+\left(\tau_{A}-Y_{A} \frac{\partial C_{A}}{\partial V_{A}}\right) \frac{\partial X_{A}^{r}}{\partial t_{A}}=0, \\
& \left(t_{A}-Y_{A} \frac{\partial C_{A}}{\partial V_{A}}\right) \frac{\partial Y_{A}^{r}}{\partial \tau_{A}}+\left(\tau_{A}-Y_{A} \frac{\partial C_{A}}{\partial V_{A}}\right) \frac{\partial X_{A}^{r}}{\partial \tau_{A}}+X_{A}^{r}=0,
\end{aligned}
$$


where $V_{A}=X_{A}+Y_{A}$ is the total (local plus transit) traffic volume in country A. In Appendix 1 we show that (9) and (10) imply the following results (analogous results hold for country B):

$$
\begin{aligned}
& t_{A}=L M E C_{A}+X_{A} \frac{\partial C_{A}}{\partial V_{A}} \\
& \tau_{A}=L M E C_{A}-X_{A}\left[\frac{\frac{\partial Y_{A}^{r}}{\partial t_{A}}}{\frac{\partial z_{A}}{\partial t_{A}} \frac{\partial X_{A}^{r}}{\partial \tau_{A}}}\right] \\
& \tau_{A}>t_{A} .
\end{aligned}
$$

In these expressions, $L M E C_{A}$ is the local direct marginal external congestion cost, defined as:

$$
L M E C_{A}=Y_{A} \frac{\partial C_{A}}{\partial V_{A}}=Y_{A} \frac{\partial C_{A}}{\partial X_{A}}=Y_{A} \frac{\partial C_{A}}{\partial Y_{A}}
$$

It captures the effect of extra traffic on the generalised user cost in country $A$, multiplied by the number of local users of the link. It is a direct marginal external cost in that it does not take into account feedback effects on demand. Note that country $A$ does not consider the time losses imposed on transit traffic through $A$ as part of the relevant local marginal external cost.

Expressions (11), (12) and (13) imply that the local and transit tolls both exceed the local marginal external cost; moreover, the transit toll is strictly larger than the local toll. These results immediately follows from the signs of the reduced-form demand price effects, see (6) and (7). Transit taxes higher than taxes on local transport are consistent with the tax competition literature; they simply reflect tax exporting behaviour (see, e.g., Arnott and Grieson (1981), Wilson (1999)). However, that the local toll exceeds LMEC is follows from the interaction of local and transit demand in generating congestion. As a consequence, the true opportunity cost of an increase in local traffic not only covers the 
local direct marginal external cost but also the opportunity cost of the lost tax revenues

on transit: more local traffic implies higher congestion and hence less transit demand. ${ }^{6}$

\subsection{Optimal tolls in a parallel network: uniform tolls}

Suppose countries are limited to uniform tolls, i.e., the toll is restricted to be the same for local and transit trips. Denote the uniform tolls by $\theta_{A}$ and $\theta_{B}$ in regions $\mathrm{A}$ and $\mathrm{B}$, respectively, where $\theta_{i}=\tau_{i}=t_{i}(i=A, B)$.

Solving the equilibrium conditions (2), (3) and (4) for the case of uniform tolls now yields the system:

$$
\begin{aligned}
& X_{A}^{r}\left[\theta_{A}, \theta_{B}\right] \\
& X_{B}^{r}\left[\theta_{A}, \theta_{B}\right] \\
& Y_{A}^{r}\left[\theta_{A}, \theta_{B}\right] \\
& Y_{B}^{r}\left[\theta_{A}, \theta_{B}\right]
\end{aligned}
$$

In Appendix 2 we show that the reduced-form demand functions for A (analogous results hold for B) have the following properties:

$$
\frac{\partial X_{A}^{r}}{\partial \theta_{A}}<0, \frac{\partial X_{A}^{r}}{\partial \theta_{B}}>0, \frac{\partial Y_{A}^{r}}{\partial \theta_{A}}<0, \frac{\partial Y_{A}^{r}}{\partial \theta_{B}}<0
$$

6 Note that, for the specific model structure considered here, it turns out that the local tax equals the global direct marginal external cost of a traffic increase in country A, defined as

$$
G M E C_{A}=\left(Y_{A}+X_{A}\right) \frac{\partial C_{A}}{\partial V_{A}}=V_{A} \frac{\partial C_{A}}{\partial V_{A}} .
$$

The global marginal external cost is the increase in generalised cost from an extra unit of traffic, multiplied by the total number of road users in $A$. That the local tax exceeds the local marginal external cost is a general result, that it precisely equals the global marginal external cost is an artefact of the model structure. The intuition can be understood by the definition of the generalised cost in combination with the structure of the objective function. Transit traffic is indifferent between paying one Euro more in time costs and one Euro more in transit tolls. The government that hosts the transit traffic obviously prefers the transit toll. Therefore, the opportunity cost of allowing one more unit of local traffic equals the local marginal external cost plus the total transit revenue foregone through the increase in average costs for transit traffic. The definition of generalised costs implies that the increase in average costs (the marginal external cost of the transit traffic) equals the total transit revenue foregone. 
Again, an increase in the uniform tax in a region is expected to have a double effect on transit (local) demand in that region: a direct negative effect, and an indirect positive effect due to the lower volume of local (transit) traffic. The above results show that the former effect dominates the indirect feedback effect ${ }^{7}$. Moreover, we also find that an increase in the uniform tax abroad (e.g. in B) raises transit demand but reduces local demand (e.g., in A). The reason is simply that overall transit demand is shifted from B to $\mathrm{A}$, which in turn raises congestion in A and hence lowers local demand in A.

To determine the optimal uniform toll for country A, consider the first-order condition to the problem

$$
\operatorname{Max}_{\theta_{A}} \quad W_{A}=\int_{0}^{Y_{A}}\left(P_{A}^{Y}\left(Y_{A}\right)\right) d Y_{A}-g_{A}^{Y} * Y_{A}+\theta_{A}\left(Y_{A}+X_{A}\right)
$$

This can be written as, after simple manipulation (see Appendix 2):

$$
\theta_{A}=Y_{A} \frac{\partial C_{A}}{\partial V_{A}}-\frac{X_{A}^{r}}{\frac{\partial Y_{A}^{r}}{\partial \theta_{A}}+\frac{\partial X_{A}^{r}}{\partial \theta_{A}}}
$$

It immediately follows that $\theta_{A}>L M E C_{A}$, unless transit in $\mathrm{A}$ is zero. The optimal uniform toll exceeds the local direct marginal external cost, and it rises with transit. Again, except for the role of congestion, this is in line with the earlier tax competition literature. Intuitively, the toll balances the distortion on the local transport market and the revenue opportunities on transit.

\subsection{Optimal tolls in a parallel network: the case of local tolls only}

Suppose the government cannot tax transit $\left(\tau_{i}=0(i=A, B)\right)$. The equilibrium conditions (2), (3) and (4) can then be solved for the system of reduced form demand functions that depend on the local tolls in both countries:

\footnotetext{
${ }^{7}$ For transit, this is in line with our earlier finding that, in the case of differentiated taxes, in absolute value the effect of the transit tax exceeded that of the tax on local transport.
} 


$$
\begin{aligned}
& X_{A}^{r}\left[t_{A}, t_{B}\right] \\
& X_{B}^{r}\left[t_{A}, t_{B}\right] \\
& Y_{A}^{r}\left[t_{A}, t_{B}\right] \\
& Y_{B}^{r}\left[t_{A}, t_{B}\right]
\end{aligned}
$$

The signs of these demand equations are identical to the reduced demand functions of the differentiated toll case. Own price effects are negative, cross price effects positive.

The first-order condition to the problem for country A:

$$
\operatorname{Max}_{t_{A}} \quad W_{A}=\int_{0}^{Y_{A}}\left(P_{A}^{Y}\left(Y_{A}\right)\right) d Y_{A}-g_{A}^{Y} * Y_{A}+t_{A} Y_{A}
$$

implies:

$$
t_{A}=Y_{A} \frac{\partial C_{A}}{\partial V_{A}}\left[1+\frac{\frac{\partial X_{A}^{r}}{\partial t_{A}}}{\frac{\partial Y_{A}^{r}}{\partial t_{A}}}\right]
$$

where the term between square brackets is shown to be positive (see Appendix 3). Using the signs of the demand functions this implies that the tax is positive but smaller than local marginal external cost:

$$
0<t_{A}<L M E C_{A}
$$

This result underscores the importance of the interaction between local and transit traffic. To understand the intuition, note that the toll reduces local transport demand, a welfare-raising correction for the externality this traffic imposes. However, the reduction in local traffic reduces the average time cost for transit and attracts more transit; this decreases local welfare and induces a tax below LMEC. If transit traffic reacts very strongly to an average travel time cost decrease, it may be optimal to set the tax very low so as to avoid attracting too much transit. Note that, if the local toll had no affect on transit, a toll equal to LMEC would be optimal. 


\subsection{Optimal tolls under various tolling systems: summary}

Table 2 and Theorem 1 below summarise the main findings of this section under the maintained assumption that there is both transit and local traffic at the equilibrium considered.

\section{THEOREM 1}

a. Optimal differentiated tolls imply that (i) local and transit tolls both exceed the local marginal external cost; (ii) the transit toll is strictly larger than the local toll.

b. The optimal uniform toll exceeds the local marginal external cost. Moreover, it will be higher the more important is transit traffic through the country.

c. If only local traffic can be tolled, the optimal toll is positive but smaller than the local marginal external cost.

Results show that a wide range of optimal tolling schemes is possible. Some of these may well be consistent with observed practice. For example, the use of vignettes in some countries comes close to the idea of tax differentiation, and it indeed implies the potential for tax exporting to foreigners. Importantly, our findings may help to explain why small open economies unable to tax transit favour taxes on local traffic that are substantially below marginal congestion costs. In fact, such countries are often slow to accept congestion taxes or are even explicitly opposed to their introduction, unless transit can also be taxed (Belgium, Netherlands, etc.). The results presented here for the case 'local tolls only' are not inconsistent with this type of behaviour. 
Table 2: Summary of optimal tolling rules

\begin{tabular}{|l|l|l|}
\hline Tolling regime & $\begin{array}{l}\text { Results } \\
\text { optimal tolls }\end{array}$ & on \\
\hline Differentiated tolls & $\begin{array}{l}\tau_{i}>L M E C_{i} \\
t_{i}>L M E C_{i} \\
\tau_{i}>t_{i}\end{array}$ & $\begin{array}{l}\text { - Local and transit toll exceed local } \\
\text { marginal external congestion cost } \\
\text { - Transit toll exceeds local toll }\end{array}$ \\
\hline Uniform tolls & $\begin{array}{l}\theta_{i}=\tau_{i}=t_{i} \\
\theta_{i}>L M E C_{i}\end{array}$ & $\begin{array}{l}\text { - Uniform toll exceeds local marginal } \\
\text { external congestion cost }\end{array}$ \\
\hline Local tolls only & $0<t_{i}<L M E C_{i}$ & $\begin{array}{l}\text { - Tolls on local traffic are positive but } \\
\text { below marginal external congestion } \\
\text { cost }\end{array}$ \\
\hline
\end{tabular}

\section{Nash equilibria for linear cost and demand functions}

The optimal tax rules derived in the previous section under different tolling systems implicitly define countries' reaction functions to taxes abroad. To formally study their properties and to analyse the resulting Nash equilibria, it is instructive to impose more structure on the problem. In this section we therefore focus on linear demand and cost functions. These simplifications also pave the way for the numerical analysis that follows in Section 4.

Specifically, we use the following linear inverse demand functions:

$$
\begin{aligned}
& P^{X}(X)=a-b X \\
& P_{A}^{Y}\left(Y_{A}\right)=c_{A}-d_{A} Y_{A} \\
& P_{B}^{Y}\left(Y_{B}\right)=c_{B}-d_{B} Y_{B} \\
& \text { with } a, b, c_{A}, d_{A}, c_{B}, d_{B}>0
\end{aligned}
$$

Cost functions for transport time (and resources) are specified as:

$$
\begin{aligned}
& C_{A}\left(X_{A}+Y_{A}\right)=\alpha_{A}+\beta_{A}\left(X_{A}+Y_{A}\right) \\
& C_{B}\left(X_{B}+Y_{B}\right)=\alpha_{B}+\beta_{B}\left(X_{B}+Y_{B}\right) \\
& \text { with } \alpha, \beta>0
\end{aligned}
$$

As before, we only consider the general case where both regions have transit and local transport. The algebraic derivations to arrive at the reaction functions and to show the 
existence of a Nash equilibrium for the various tolling regimes are conceptually simple, but somewhat tedious. We have therefore delegated the derivations to Appendix 4 and limited the discussion here to the economic implications of our findings.

\subsection{Reaction functions and Nash equilibrium: differentiated tolls}

The reaction functions for country A ( analogous results hold for B) are given by the following linear expressions:

$$
\begin{aligned}
& \tau_{A}=c_{A}^{\tau}-\left(\frac{1}{2} \frac{\gamma_{2}^{A}}{\gamma_{1}^{A}}\right) \tau_{B}-\left(\frac{1}{2} \frac{\gamma_{4}^{A}}{\gamma_{1}^{A}}\right) t_{B} \\
& t_{A}=c_{A}^{t}+\left(\frac{1}{2} \frac{\gamma_{2}^{A}}{\gamma_{1}^{A}} K^{A}\right) \tau_{B}+\left(\frac{1}{2} \frac{\gamma_{4}^{A}}{\gamma_{1}^{A}} K^{A}\right) t_{B}
\end{aligned}
$$

where the coefficients are explicitly defined in Appendix 4. Here it suffices to note:

$$
\begin{gathered}
\gamma_{1}^{A}<0, \gamma_{2}^{A}>0, \gamma_{4}^{A}<0 \\
\left|\gamma_{2}^{A}\right|>\left|\gamma_{4}^{A}\right| \\
-1<K^{A}<0
\end{gathered}
$$

Interpretation of the signs of the foreign taxes on optimal local taxes in $\mathrm{A}$ is then clear. We find that an increase in the transit tax abroad induces country A to optimally adjust both its transit tax and the tax on local traffic upwards, but that the impact on the transit tax is larger than the effect on the local tax. Why is this the case? The higher tax on transit in $\mathrm{B}$ reduces transit there and raises transit demand in A. This increases local congestion in A. The optimal response in A is therefore to raise both taxes. Similarly, a higher local tax in B induces country A to optimally reduce transit as well as local taxes in $\mathrm{A}$. The higher tax in $\mathrm{B}$ reduces congestion in $\mathrm{B}$ and makes $\mathrm{B}$ relatively more and $\mathrm{A}$ relatively less attractive to transit traffic. This also reduces both congestion and tax revenues in A. To compensate country A raises its tax rate on local traffic; this increases congestion but raises tax revenues.

In Appendix 4 we formally show existence of a Nash equilibrium. Not surprisingly, explicitly solving for the equilibrium tax rates does not yield extra economic insights. 
Therefore, to study the properties of the equilibrium in function of a number of crucial parameters describing the tax competition problem (e.g., the size of the country, the importance of transit etc.), we resort to numerical analysis in Section 4 below.

\subsection{Reaction functions and Nash equilibrium: uniform tolls}

The reaction function for country $\mathrm{A}$ as a function of the uniform tax rate in B is given by the linear relation:

$$
\theta_{A}=\frac{c_{2}^{\text {tuA }}}{c_{1}^{\text {tuA }}}+\frac{c_{3}^{\text {tuA }}}{c_{1}^{\text {tuA }}} \theta_{B}
$$

where (see Appendix 4) $c_{1}^{\text {tuA }}>0, c_{2}^{\text {tuA }}>0, c_{3}^{\text {tuA }}>0$. An analogous result holds for B. This shows that the reaction functions are upward sloping. A Nash equilibrium can again be shown to exist.

\subsection{Reaction functions and Nash equilibrium: local tolls only}

The reaction function for country A is shown to be:

$$
t_{A}=\frac{c_{2}^{t l A}}{c_{1}^{t l A}}+\frac{c_{3}^{t l A}}{c_{1}^{t / A}} t_{B}
$$

where

$$
c_{1}^{t l A}>0, c_{2}^{t l A}>0, c_{3}^{t l A}>0 .
$$

Again, the slope of the reaction functions is positive, and (assuming both types of traffic exist at the equilibrium) existence of a Nash equilibrium can be shown, see Appendix 4 .

\section{Numerical illustration}

In order to illustrate the theoretical analysis, a numerical model is used that fully corresponds to the linear model developed in the previous section. The data represent realistic orders of magnitude for the situations modelled above, but they do not 
correspond to one particular real-world example. The advantage of such a 'generic' application is that it allows us to numerically illustrate the sensitivity of the results with respect to the importance of transit and to series of parameters that reflect some observed real-world differences between countries.

We start the discussion by analysing a central and fully symmetric scenario, and then consecutively consider the role of transit, of asymmetric local demand functions (reflecting differences in the relation between local demand and road capacity) and of differences in congestion functions. For each of the scenarios considered, the following equilibria are calculated:

- S1: The no toll equilibrium, to which the model is calibrated;

- S2: Nash equilibrium with differentiated tolls;

- S3: Nash-equilibrium with uniform tolls on local and transit traffic;

- S4: Nash equilibrium with local tolls only;

- S5: Centralized solution with differentiated tolls

- S6: Centralized solution with local tolls only.

In each scenario, the toll revenue is allocated to the tolling countries. Note that, by construction, we obtain interior solutions for the counterfactual scenarios.

\subsection{Central scenario}

The central scenario uses a fully symmetric version of the model, with identical congestion and local demand functions for both countries. The congestion function is a linear approximation to the French functional form for highways (Quinet (1998, p. 139)), at a reasonably congested traffic volume. The precise parameterization of all cost and demand functions is chosen so as to yield reasonable generalized price elasticities and congestion levels (including marginal external congestion cost); cf. more detail below. In

\footnotetext{
* Department of Economics, University of Antwerp, Prinsstraat 13, B-2000 Antwerp, Belgium (bruno.deborger@ua.ac.be)

${ }^{* *}$ Department of Economics, Catholic University of Leuven, Naamsestraat 69, B-3000 Leuven, Belgium (stef.proost@econ.kuleuven.ac.be)

${ }_{* * *}$ Department of Economics, University of California at Irvine, Irvine, CA 92697-5100 (kvandend@uci.edu)
} 
addition to symmetry, the central case also assumes a 50/50 distribution of transit and local traffic in each country, in the zero-toll reference situation.

Table 3 shows some basic properties of the demand and cost functions used, and the associated reference demand and cost levels. Note that transit demand is twice local demand in A or B and it is, endogenously, equally distributed over both countries. The time cost is taken to be $50 \%$ of the generalized price. The non-time component is fixed across simulations.

Table 3 Zero-toll symmetric equilibrium (central case parameterization)

\begin{tabular}{|l|c|c|c|c|}
\hline & Intercept & Slope & Level & Unit \\
\hline Local demand, A=B & 1690 & -5.96 & 1300 & Trips \\
\hline Transit demand & 3380 & -11.92 & 2600 & Trips \\
\hline Time cost function, $\mathrm{A}=\mathrm{B}$ & 1.617 & 0.012 & 32.7 & Euro/trip \\
\hline Generalized price, $\mathrm{A}=\mathrm{B}$ & & & 65.4 & Euro/trip \\
\hline Local MEC, A=B & & & 15.5 & Euro/trip \\
\hline Global MEC, A=B & & & 31.1 & Euro/trip \\
\hline
\end{tabular}

Note: all trips are taken to be $100 \mathrm{~km}$ long; the trip levels are hourly levels

Calculated results for each of the six equilibria leads to the results summarized in Tables 4 and 5. They are easily summarized. Reassuringly, the optimal tolls nicely illustrate a number of results of the theoretical analysis. For example, at the centralised solution (S5) both transit and local tolls equal global marginal external cost. Note that, while toll differentiation is allowed in scenario S5, the resulting tolls are equal because marginal external costs are equal for both trip types. In the Nash equilibrium with differentiated tolls (S2), both the local and global toll exceed the local marginal external cost (the local toll is equal to the global marginal external congestion cost), and the transit toll exceeds the local toll. In the corresponding solution with uniform tolls (S3) the optimal toll is between the toll levels of the differentiated case. Interestingly, the optimal local toll is very low in the Nash equilibrium case where transit remains un-tolled: it amounts to 6.8 Euro relative to a global marginal external cost of 30.7.

Turn to the relative welfare levels at the different equilibria. First, observe that the Nash equilibrium with differentiated tolls is able to generate a large percentage of the maximal possible welfare gain. To see this, note that the maximal welfare gain (the gain at the 
centralised solution S5) relative to the no-toll reference equilibrium amounts to $1.58 \%$ of this reference welfare level. The Nash-equilibrium with differentiated tolls improves overall welfare by $1.47 \%$ compared to the reference case, or $93 \%$ of the maximal attainable gain. Moreover, the shares of both countries and of transit in total welfare are also fairly close to that of the centralised solution. In both cases the shares of local traffic in welfare increase substantially compared to the no-toll situation, while that of transit traffic diminishes. ${ }^{8}$ Our finding that the Nash equilibrium with differentiated tolls brings us close to the social welfare optimum implies that the welfare costs of the lack of coordination between countries seem to be relatively modest. A similar conclusion was obtained in totally different contexts by Sorensen (2000) and Parry (2003). At any rate, tolling with no coordination is much better than no tolling at all.

Second, comparing the Nash equilibrium with and without toll differentiation (S2 and S3) suggests that the uniformity constraint implies a very small overall welfare loss (0.06\%-point), despite a substantial impact on the local toll. This increases from 27.1 Euro/trip to 36.8 Euro/trip, close to the transit toll of 37.9 in the differentiated tolling case. However, this hardly affects welfare compared to the differentiated tolling case. Local welfare goes down only marginally because the reduction in local consumer surplus is almost fully offset by the increase in tax revenues, which have the same welfare weight as consumer surplus. Transit experiences only a modest welfare gain relative to the differentiated tolling case; the reason is that the toll on transit is quite similar under both the uniform and the differentiated tolling case. The results indicate that the overall welfare effects of uniform versus differentiated tolls are quite similar, although the distribution between local and transit welfare obviously substantially differs. Finally, the uniformity restriction does not protect transit from substantial welfare losses compared to the no toll situation.

Third, consider the cases where transit trips cannot be tolled. These scenarios are of interest because zero tolls on transit traffic mimics current (and possibly future)

\footnotetext{
${ }^{8}$ The resulting welfare loss for transit could be expected, as transit trips are priced below marginal social costs in the reference equilibrium. A toll is needed for reasons of efficiency, but transit does not share in the toll revenues.
} 
conditions in Europe, at least for transit countries that are small enough to allow transit to pass without taking fuel. We find the performance of both the Nash and the centralised outcome (S4 and S6) to be substantially worse than in the cases where transit is tolled. The Nash equilibrium without transit tolls (S4) generates only $21.5 \%$ of the maximal possible welfare gain (S5) and $23 \%$ of the welfare gain in the Nash equilibrium with differentiated tolls (S2). Note also that the centralised solution with zero transit tolls performs worse than both the Nash equilibria with and without toll differentiation.

Our findings suggest, therefore, that welfare losses are much more substantial when transit remains un-tolled than when tolls on local and transit transport are required to be uniform. Moreover, it also seems that not tolling transit, a substantial fraction of total traffic, is equally if not more important for welfare than tax competition itself. Moving from the centralised solution with taxes on both local and transit traffic to a centralised situation with no toll on transit (compare S5 and S6), we see that the tax on local traffic only falls marginally below marginal external cost. The large welfare difference is uniquely due to un-tolled transit. Introducing tax competition under the zero transit toll constraint then does introduce an additional welfare loss (compare S6 and S4): countries find it in their best interest to tax local traffic at far less than the global marginal external congestion cost. As countries care about local welfare only, they set local tolls at a low level, so encouraging local trip demand and indirectly discouraging transit trips.

To summarise, our numerical findings so far indicate that:

- It is important to introduce some form of transit tolling; the welfare effects of tolling transit are large.

- The precise type of transit tolling (uniform local and transit tolls versus differentiated transit tolls) has relatively small welfare effects.

- The welfare losses due to not tolling transit seem to be at least as important as the losses due to tax competition itself.

- A uniformity restriction for local and transit tolls does not protect transit from large welfare losses. 


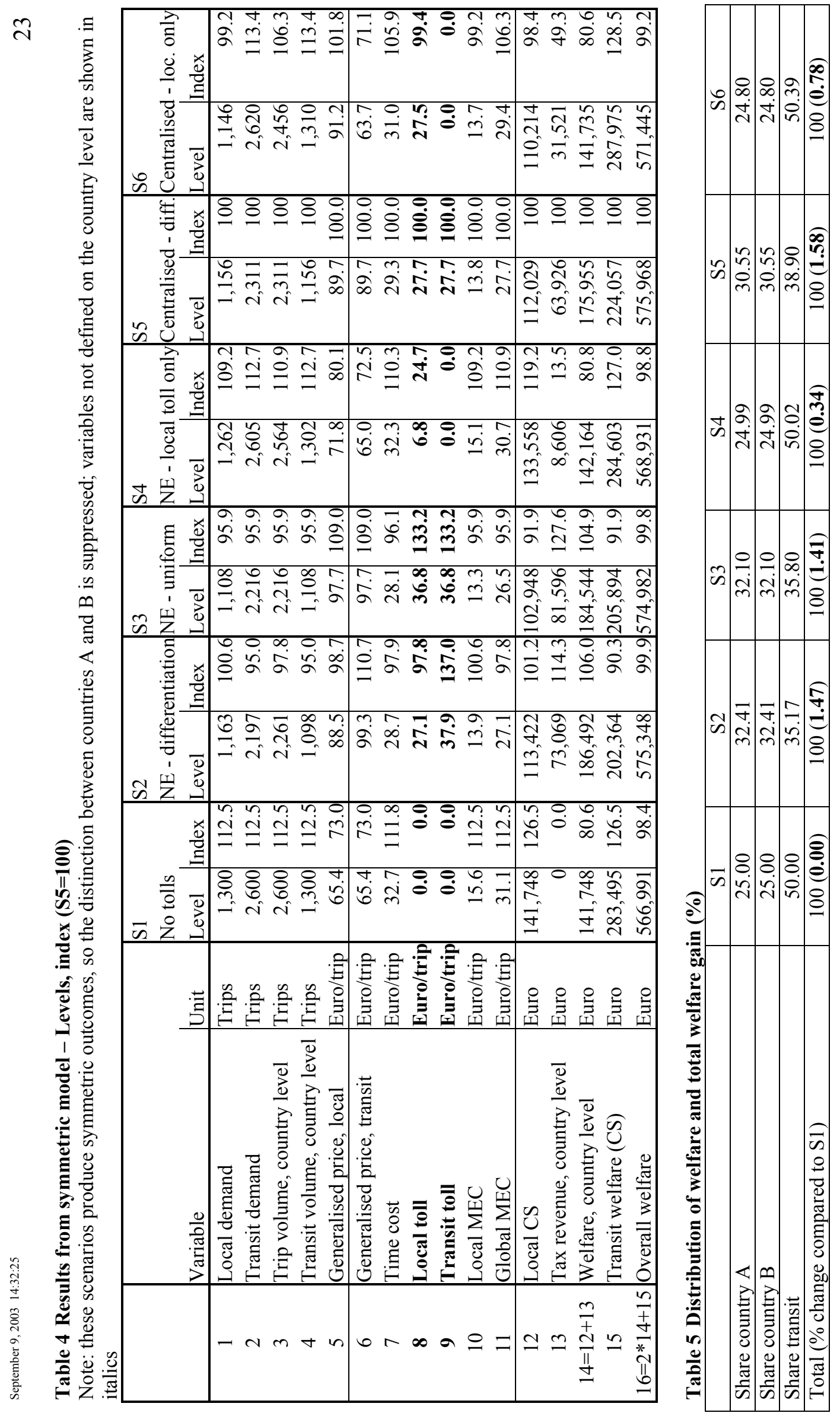




\subsection{The importance of the share of transit in the no-toll equilibrium}

The transit share in the central scenario was $50 \%$ in both countries. In this sub-section we briefly illustrate the impact of changing the relative importance of transit; apart from that, the countries are still assumed to be symmetric.

First consider Figure 2 below. This shows, for the Nash equilibrium tolls with differentiated tolling, the effects of varying the share of transit between $1 \%$ and $50 \%$, while keeping the notoll total traffic volumes at the levels of the central scenario (so this reflects 'constant congestion' compared to the central scenario). We see that the transit toll rises dramatically as the share of transit increases, while the local transit toll slightly declines. This latter effect follows from the higher transit toll which leads to lower traffic levels and, therefore, lower (global) marginal external costs. Finally, note that as the transit share goes to zero, the model converges to marginal social cost pricing for both transport types.

Figure 2 Tolls as a function of no-toll transit share

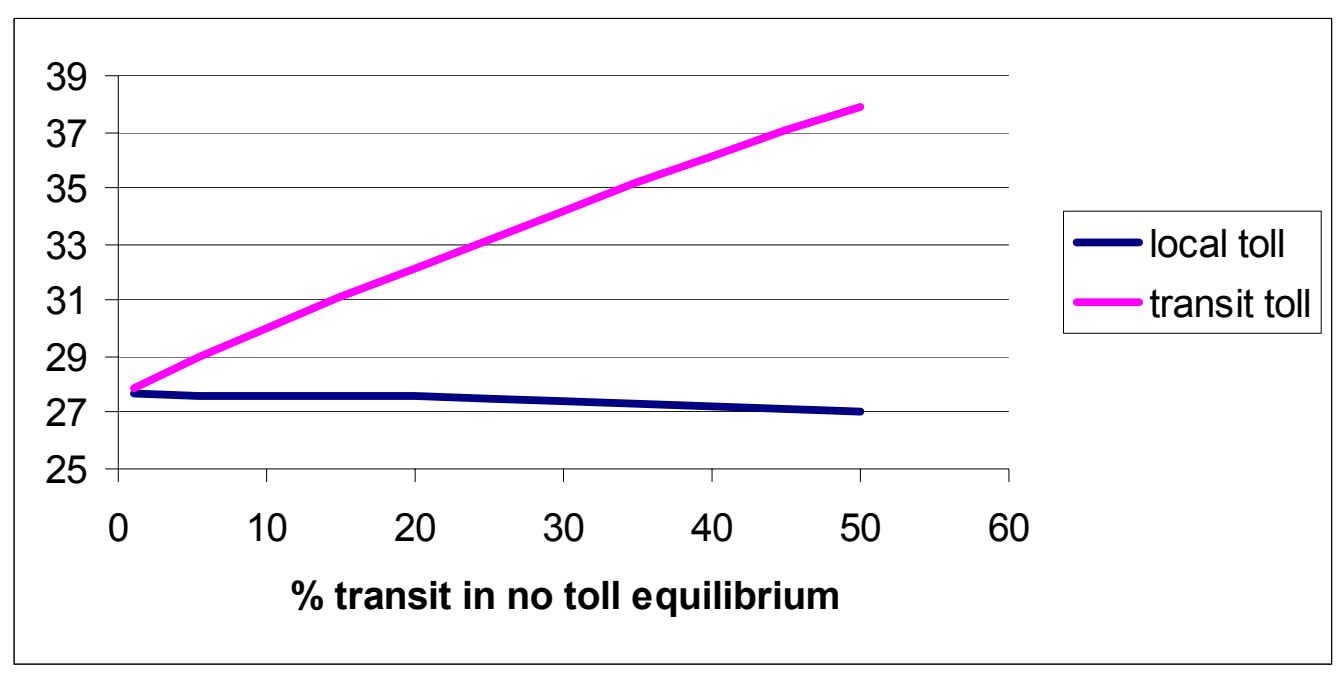

Next, we try to find out if the qualitative results concerning the welfare impacts of various pricing constraints depend on the importance of transit. In order to do this, in Tables 6 and 7 we reconsider scenarios S1 - S6 for a reference transit share of 10\% (instead of 50\% in Tables 4 and 5). Except for those already mentioned, the qualitative differences are limited, with three exceptions. First, the lower transit share induces a much higher local toll in the Nash equilibrium with zero tolls on transit. The reason is that, for a given increase in tax revenue on 
local traffic, the increase in congestion due to rising transit is smaller than before. Second, the welfare loss from not coordinating between countries (compare S2 and S5) is even smaller than in the central scenario, as there is less transit and therefore less of a conflict between local and global welfare. Third, not surprisingly, with low transit shares the inability to toll transit traffic is much less detrimental than in the central scenario. In scenario S4, the Nash equilibrium with a local toll only, $62 \%$ of the gain from the gain in the Nash equilibrium with differentiation (S2) is obtained. It is still the case that the Nash equilibrium with uniform tolls (S3) does better than welfare maximisation with local tolls only (S6). 


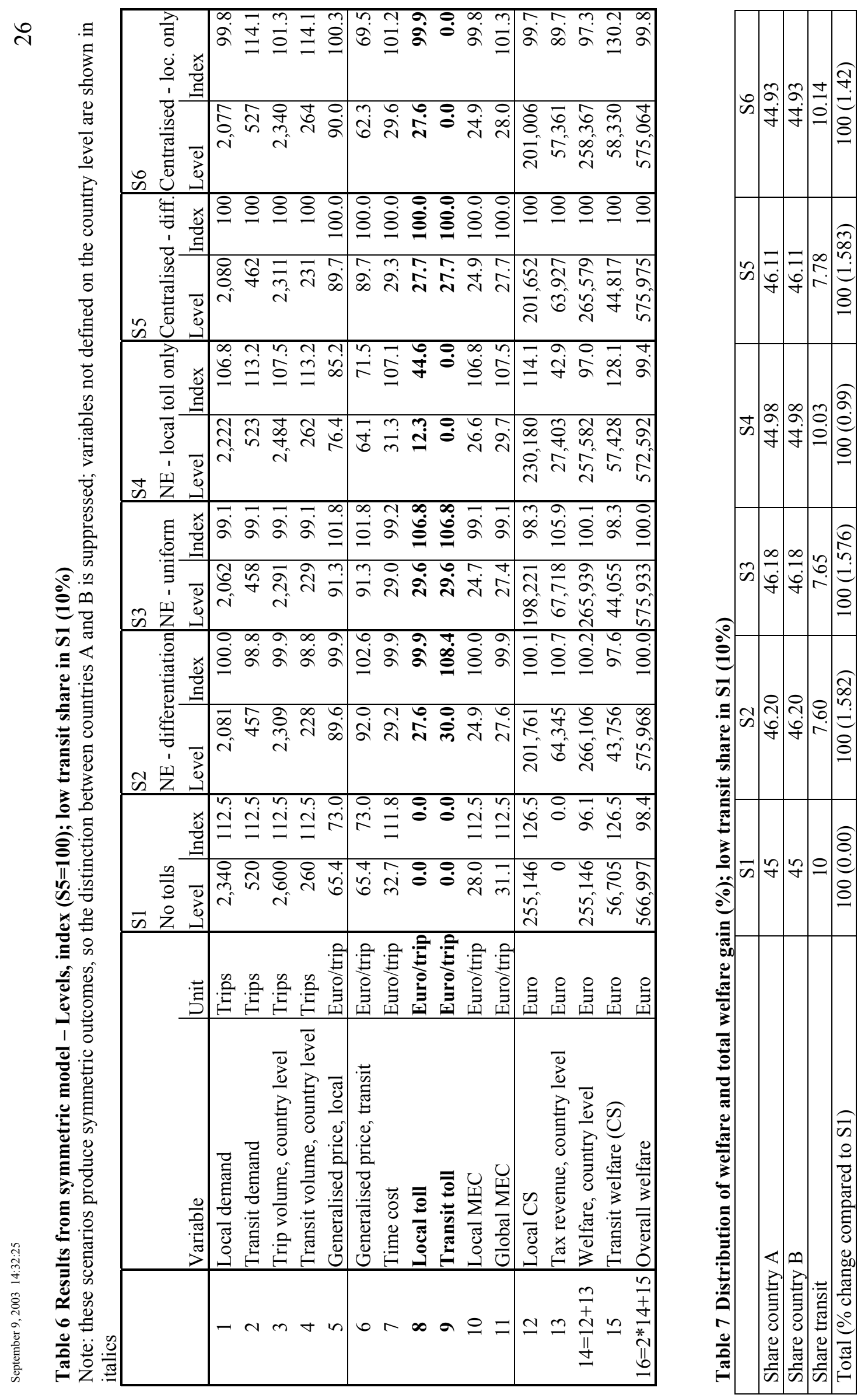




\subsection{The effects of asymmetry between countries}

\subsubsection{Asymmetrical local demand functions}

In this sub-section we consider the effect of differences between countries in local demand functions. More precisely, (i) the transit demand function is assumed to be the same as before; (ii) the sum of local demand over both countries is the same as before; (iii) but, local demand in country $\mathrm{A}$ is decreased and that in country B is increased (in the reference case, the no-toll equilibrium). The local demand functions are adapted accordingly (implying both a shift and a change in slope, as the reference elasticity of demand is held constant).

To interpret the economics of the simulations reported here, note that aggregate trip demand for the whole network in the no-toll equilibrium is held at the level of the central scenario, but that only the distribution of local traffic (and, as a consequence, of equilibrium transit demand) between countries is changed. In other words, we look at differences in local demand relative to the available road capacity: for any given level of transit demand, country A has lower congestion than country B. Therefore, the scenario could be interpreted as the case of a densely (B) populated versus a sparsely (A) populated country. Given constant road capacity, more transit is automatically attracted to A. The scenario therefore also reflects differences in the potential of countries to attract transit.

In order to keep the analysis transparent, we limit the discussion to the effects of the described asymmetry for the reference zero toll scenario and for the Nash equilibrium with differentiated tolls. Results are in Table 8, the structure of which is necessarily somewhat different from earlier tables. The top part of the table first describes the effects of the asymmetry on the reference equilibrium when we decrease, from left to right, local demand in country A; correspondingly, local demand in B rises. Since road capacity does not change, a larger share of overall transit demand, which is constant, is attracted to Country A. By construction, the local marginal congestion cost in Country A decreases, that in Country B increases and, in the reference equilibrium, the generalized cost and the global marginal congestion costs are the same as in the central scenario in both countries. 
To get insight into the effects of asymmetric demands, the bottom part of Table 8 gives, for different levels of asymmetry, the optimal tolls for the Nash equilibrium with differentiated tolls. Moreover, it presents changes in demand, marginal cost and welfare when moving from the reference scenario to the Nash outcome. The most relevant results are the following. First, asymmetry implies a lower local toll and a higher transit toll in the low-demand Country A, with the opposite directions of change in Country B. Second, its attractiveness for transit implies that global marginal congestion costs in Country A rise (they decrease less compared to the symmetric reference); the opposite holds for B. However, note in both cases that the magnitude of these effects is limited even at very high levels of asymmetry. Third, the effect of the asymmetry on the total transit demand reduction is very small. Not surprisingly, as Country A carries more transit flow (in relative and in absolute terms), moving from the reference case to the Nash equilibrium implies a larger reduction in its share in total transit flow. Fourth, the gain from introducing the Nash differentiated tolls in Country A strongly rises when its local willingness to pay for trips becomes smaller; correspondingly, the gains for Country $\mathrm{B}$ become smaller. The reduction in total transit welfare after introduction of the differentiated tolls hardly depends on the asymmetry.

The economic interpretation is clear. This exercise suggests that a country which is in a position to attract a lot of transit traffic, because it has high road capacity and/or little local demand, will benefit a lot from a differentiated toll on local and transit traffic ${ }^{9}$. The competitive advantage that follows from having sufficient capacity that is not yet congested by local users, enables the country to raise substantial amounts of toll revenue from transit users, so increasing local welfare. The welfare potential of the competing country decreases, but transit users are hardly affected.

\footnotetext{
${ }^{9}$ This example also suggests that countries may have strategic incentives for provision of infrastructure. Endogenising capacity provision seems therefore to be a worthwhile extension of this paper.
} 


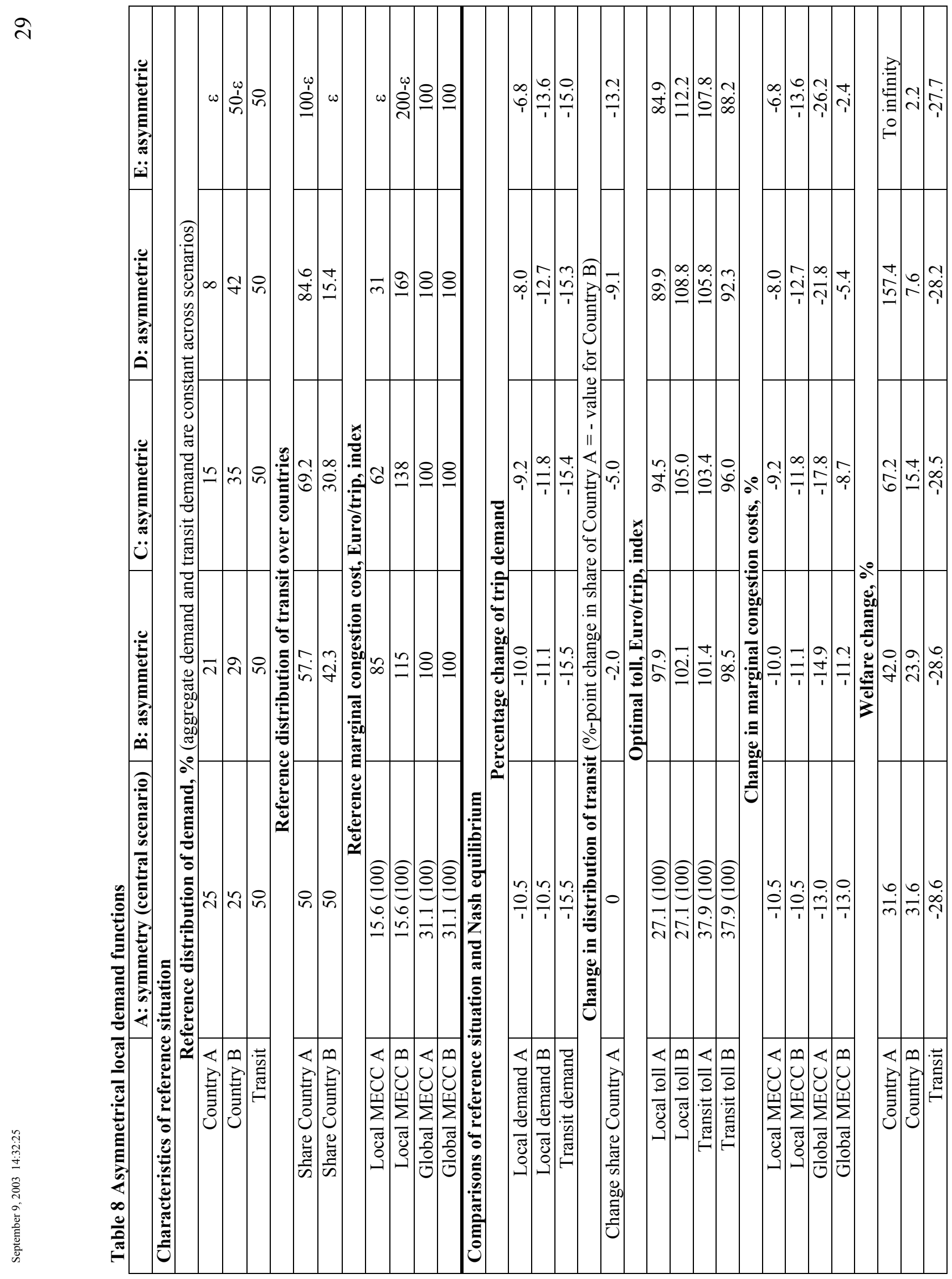




\subsubsection{Asymmetrical congestion functions}

Finally, we test the sensitivity of the results to differences in the congestion functions between countries. The scenario analysed is the following: (i) the congestion function for Country B is the same as in the central scenario; (ii) for Country A, the slope is decreased, simultaneously increasing the intercept in order to retain the volumes and travel times (in both countries) of the central scenario. Consequently, we reduce the 'congestibility' of the road in Country A, but the fixed component of travel time is simultaneously increased.

The economic interpretation of the constructed scenario is straightforward. It could be interpreted as introducing an asymmetry in the relative length and, at given traffic levels, degrees of congestion. The proposed adjustment has the same effect as making the road via Country A longer but less congested (at given traffic levels) compared to the link via country B. Loosely speaking, at given levels of local demand, transit now has the choice between a longer trip with potentially less congestion and a shorter but more congested route. From the viewpoint of transit, given the unchanged parameters for country $\mathrm{B}$, the changes for A imply that the congestibility of the whole network declines.

Consider Table 9, which has the same structure as Table 8 above. Column A is the central scenario. In columns B through D, the slope of the congestion function of Country A is gradually reduced by 5 to $15 \%$ and the intercept is adapted to keep reference volumes and distributions constant (see the top half of the table). In column E, the slope of the congestion function of Country A is reduced to epsilon, implying a virtual absence of congestion. The main results are in the bottom half of the table. First, introducing the asymmetry reduces all the optimal tolls, reflecting the decline in congestion at given traffic levels. Second, the effects are largest for the local tolls in the least congested Country A; tolls in B are much less sensitive. Third, the welfare effects of the asymmetry in congestion functions for the Nash equilibrium with toll differentiation are limited (both local and transit welfare), except in the extreme case of zero congestion in A (column E). The local welfare gains from the tolls decrease, which could be expected as the initial inefficiency from congestion becomes smaller with the network capacity increase. Overall, the simulation results suggest that countries with very different demand and congestion conditions will benefit from tolling transit. 


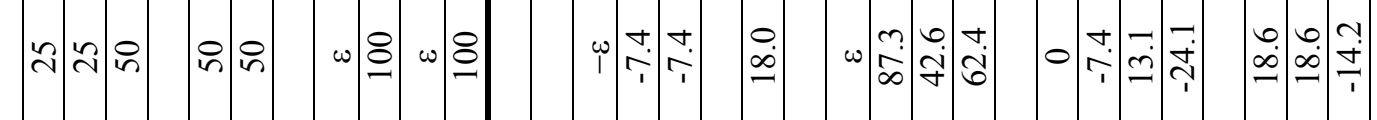

茫

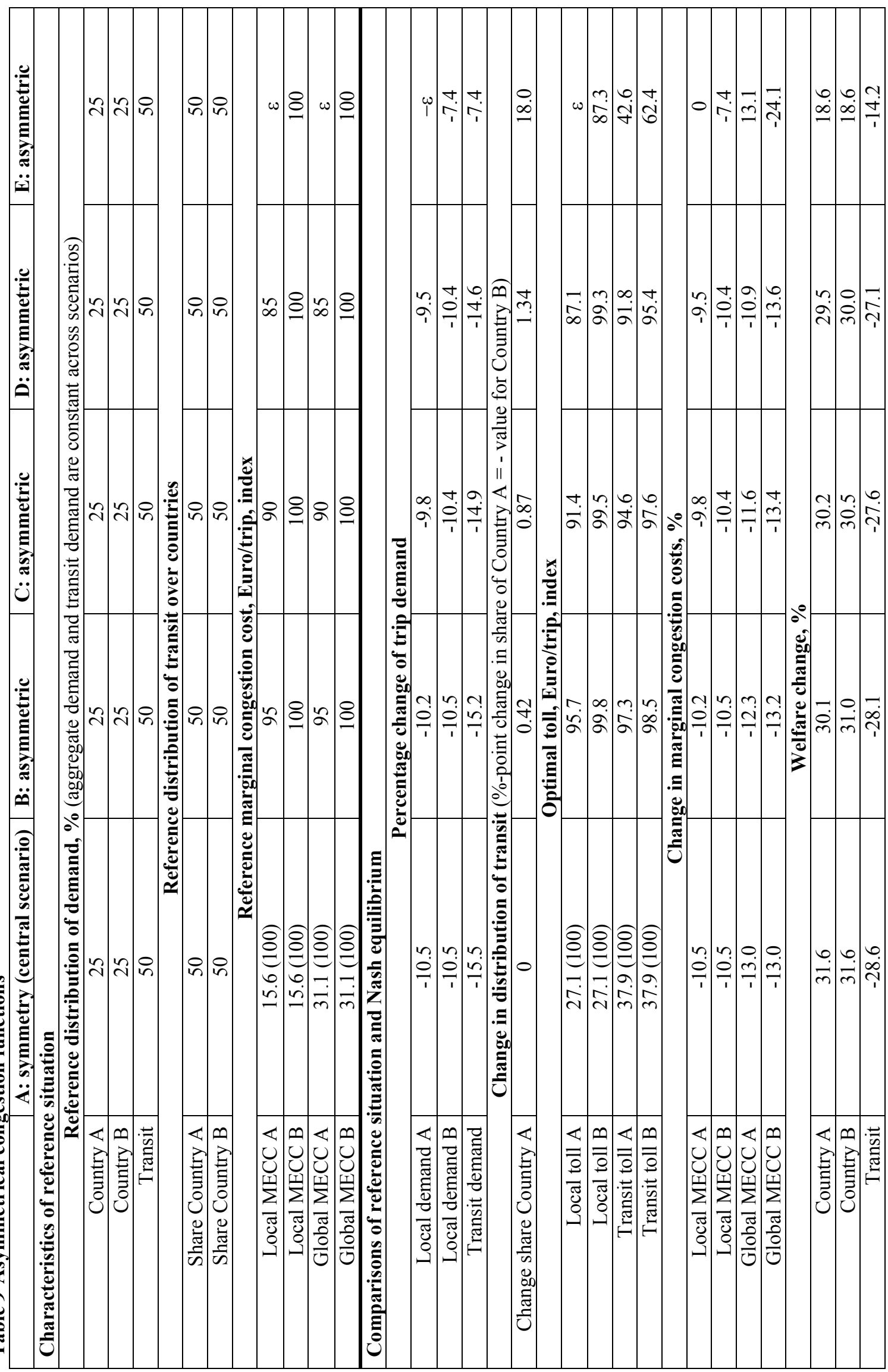




\section{Summary, conclusions and directions for future research}

In this paper we studied optimal and strategic pricing of local and transit traffic on a simple parallel network. The tolling authority on the individual links of the network was assumed to be assigned to different countries. We first theoretically analysed Nash equilibria in this setting for three types of pricing structures: differentiated tolls between local and transit traffic, uniform tolls, and local tolls only. Then a numerical model was used to illustrate the main results and to assess the welfare effects of various pricing constraints and of (the lack of) coordination between countries. Moreover, the relevance of the share of transit in total transport demand and of asymmetries between countries was numerically illustrated.

The conclusions are easily summarised. First, the welfare effects of tolling transit seem to be large, but the precise type of transit tolling has relatively small effects on efficiency improvements compared to the no tolling situation. Specifically, differentiation between local and transit tolls as compared to uniform tolls does not yield large welfare differences, although obviously tolls on transit may differ substantially. Allowing differentiated tolls in an uncoordinated setting tends to go at the expense of transit traffic. Second, the welfare effects of coordination between countries are relatively small in comparison with the welfare gains of tolling transit. The outcome when countries behave strategically but do tax transit (e.g., the Nash equilibrium with uniform tolls) yields higher welfare effects than the coordinated welfare optimum for the network as a whole when transit is not tolled. Third, the effect of higher transit shares on the Nash equilibrium with differentiated tolls is to strongly raise the transit toll and to slightly decrease the local toll. As the transit share goes to zero, the model converges to marginal social cost pricing for local traffic. Fourth, the impact of introducing asymmetries between countries is to raise welfare gains for the country with lower local demand (comparing the Nash-equilibrium to the no-toll equilibrium); welfare gains in the other country become less pronounced.

Finally, note that this paper could be extended along several lines. First, we have limited the analysis to cases where at all equilibria both local and transit transport occur in both regions. Although the case of zero local traffic is not very interesting, allowing corner solutions at zero transit does seem a relevant case to consider. Under specific conditions, countries could actually choose to eliminate all transit on their territory. Studying these conditions seems a relevant addition to the analysis of this paper. Second, different pricing instruments (road 
pricing, fuel taxes, vignettes, etc.) could be introduced. This would probably make the theoretical analysis intractable, but it would enrich the numerical results. Third, one could incorporate freight transport and analyse partial taxation of the network (e.g., toll trucks but not passengers). Fourth, the transition process of introducing tolling instruments sequentially could be explicitly studied. For example, given that one country moves from a system with local tolls only to a system with explicit transit tolling, how does this affect optimal responses by the other country? Alternatively, if a country moves from differentiated tolls towards uniform tolls, what is the optimal response for the other country? What do the resulting Nash equilibria look like?

\section{References}

Arnott, R. and R. Grieson (1981), Optimal fiscal policy for a state and local government, Journal of Urban Economics 9, 23-48.

Arnott, R., De Palma, A. and R. Lindsay (1993), A structural model of peak-period congestion, American Economic Review 83, 161-179.

Braid, R. (1996), Peak-load pricing of a transportation route with an unpriced substitute, Journal of Urban Economics 40, 179-197.

De Borger, B. and S. Proost, Eds. (2001), Reforming transport pricing in the European Union, Edward Elgar, Cheltenham.

De Borger, B., Courcelle, C. and D. Swysen (forthcoming 2003), Optimal pricing of transport externalities in an international environment: empirical evidence based on a numerical optimisation model, Regional Science and Urban Economics.

de Palma, A. and R. Lindsey (2000), Private toll roads: a dynamic equilibrium analysis, Annals of Regional Science, 34, 1, 13-35

Kanbur, A. and M. Keen (1993), Jeux sans frontières: tax competition when countries differ in size, American Economic Review 83, 877-892.

Levinson D., 2001, Why States Toll - An empirical model of finance choice, Journal of Transport Economics and Policy, 35, 2, 223-238

Liu, L. and J.F. McDonald (1998), Efficient congestion tolls in the presence of unpriced congestion: a peak and off-peak simulation model, Journal of Urban Economics 44, 352366. 
Mintz, J. and H. Tulkens (1986), Commodity taxation between member states of a federation: equilibrium and efficiency, Journal of Public Economics 29, 173-197.

Parry, I., 2003, How large are the welfare costs of tax competition, Journal of Urban Economics 54, 39-60.

Quinet E., 1998, Principes d'Economie des Transports, Economica, Paris

Sinn H.-W., 2003, The New Systems Competition, Blackwell Publishing, Oxford, UK, 228 pp.

Small, K. (1983), The incidence of congestion tolls, Journal of Urban Economics 13, 90-111.

Small, K. and Yan (2001), The value of "Value Pricing" of roads: second best pricing and product differentiation, (working paper RFF 00-08, January 2000), JUE ???

Sorensen, P. (2000), Tax coordination: its desirability and redistributional implications, Economic Policy 15, 431-472.

Verhoef, E., Nijkamp, P. and P. Rietveld (1996), Second-best congestion pricing: the case of an untolled alternative, Journal of Urban Economics 40, 279-302.

Verhoef, E. and K. Small (2003), Product differentiation on roads: second-best congestion pricing with heterogeneity under public and private ownership, Irvine economics paper 99-00-01

Wildasin, D. (1989), Interjurisdictional capital mobility: fiscal externality and a corrective subsidy, Journal of Urban Economics 25, 193-213.

Wilson, J.S. (1999), Theories of tax competition, National Tax Journal LII, 269-304. 


\section{Appendix 1: Detailed analysis of the case of differentiated tolls}

In this appendix we study in more detail the case of differentiated tolls on local and transit transport. We derive the reduced form demand system and discuss its properties, and we derive the optimal toll results presented in the main body of the paper.

\section{The reduced-form demand system}

Using (1) and focusing on the case where there is local and transit traffic in both regions, the system consisting of (2), (3) and (4) can be reformulated as

$$
\begin{gathered}
P^{X}\left(X_{A}+X_{B}\right)=C_{A}\left(X_{A}+Y_{A}\right)+\tau_{A} \\
P^{X}\left(X_{A}+X_{B}\right)=C_{B}\left(X_{B}+Y_{B}\right)+\tau_{B} \\
P_{A}^{Y}\left(Y_{A}\right)=C_{A}\left(X_{A}+Y_{A}\right)+t_{A} \\
P_{B}^{Y}\left(Y_{B}\right)=C_{B}\left(X_{B}+Y_{B}\right)+t_{B}
\end{gathered}
$$

This system of four equations can easily be solved for the reduced form demand functions as functions of the four tax rates. A particularly instructive way to do this is to first solve (A.3) and (A.4) separately for the demands for local transport as a function of transit demands and local tax rates in a given region:

$$
\begin{aligned}
& Y_{A}=z_{A}\left(X_{A}, t_{A}\right) \\
& Y_{B}=z_{B}\left(X_{B}, t_{B}\right)
\end{aligned}
$$

Note that application of the implicit function theorem to (A.3) implies:

$$
\begin{aligned}
& \frac{\partial z_{A}}{\partial X_{A}}=\frac{\frac{\partial C_{A}}{\partial V_{A}}}{\frac{\partial P_{A}^{Y}}{\partial Y_{A}}-\frac{\partial C_{A}}{\partial V_{A}}}<0 \\
& \frac{\partial z_{A}}{\partial t_{A}}=\frac{1}{\frac{\partial P_{A}^{Y}}{\partial Y_{A}}-\frac{\partial C_{A}}{\partial V_{A}}}<0
\end{aligned}
$$

where 


$$
V_{A}=X_{A}+Y_{A}
$$

is the total transport volume in A. Using (A.4), an analogous result is derived for B. Interpretation is simple: an exogenous increase in transit in a given region reduces the demand for local transport, as it raises local congestion and hence generalised user cost. Raising the local tax, at a given transit level, reduces local demand for transport.

Substituting (A.5)-(A.6) into (A.1) and (A.2) yields:

$$
\begin{gathered}
P^{X}\left(X_{A}+X_{B}\right)=C_{A}\left[X_{A}+z_{A}\left(X_{A}, t_{A}\right)\right]+\tau_{A} \\
P^{X}\left(X_{A}+X_{B}\right)=C_{B}\left[X_{B}+z_{B}\left(X_{B}, t_{B}\right)\right]+\tau_{B}
\end{gathered}
$$

The solution of this system yields the reduced-form demand functions for transit, denoted in the main body of the paper as $X_{A}^{r}\left[\tau_{A}, t_{A}, \tau_{B}, t_{B}\right]$ and $X_{B}^{r}\left[\tau_{A}, t_{A}, \tau_{B}, t_{B}\right]$, respectively. To determine the signs of the various tax effects on transit demands, totally differentiate system (A.9)-(A.10) and write the result in matrix notation:

$$
\left[\begin{array}{cc}
\frac{\partial P^{X}}{\partial X}-\frac{\partial C_{A}}{\partial V_{A}}\left(1+\frac{\partial z_{A}}{\partial X_{A}}\right) & \frac{\partial P^{X}}{\partial X} \\
\frac{\partial P^{X}}{\partial X} & \frac{\partial P^{X}}{\partial X}-\frac{\partial C_{B}}{\partial V_{B}}\left(1+\frac{\partial z_{B}}{\partial X_{B}}\right)
\end{array}\right]\left[\begin{array}{l}
d X_{A} \\
d X_{B}
\end{array}\right]=\left[\begin{array}{l}
\frac{\partial C_{A}}{\partial V_{A}} \frac{\partial z_{A}}{\partial t_{A}} d t_{A}+d \tau_{A} \\
\frac{\partial C_{B}}{\partial V_{B}} \frac{\partial z_{B}}{\partial t_{B}} d t_{B}+d \tau_{B}
\end{array}\right]
$$

Applying Cramers' rule then yields, after simple algebra, the effects of tax changes on demand in A (analogous results hold for B):

$$
\begin{aligned}
& \frac{d X_{A}}{d t_{A}}=\frac{1}{\Delta}\left\{\left(\frac{\partial C_{A}}{\partial V_{A}} \frac{\partial z_{A}}{\partial t_{A}}\right)\left[\frac{\partial P^{X}}{\partial X}-\frac{\partial C_{B}}{\partial V_{B}}\left(1+\frac{\partial z_{B}}{\partial X_{B}}\right)\right]\right\} \\
& \frac{d X_{A}}{d \tau_{A}}=\frac{1}{\Delta}\left[\frac{\partial P^{X}}{\partial X}-\frac{\partial C_{B}}{\partial V_{B}}\left(1+\frac{\partial z_{B}}{\partial X_{B}}\right)\right] \\
& \frac{d X_{A}}{d t_{B}}=-\frac{1}{\Delta}\left(\frac{\partial P^{X}}{\partial X} \frac{\partial C_{B}}{\partial V_{B}} \frac{\partial z_{B}}{\partial t_{B}}\right) \\
& \frac{d X_{A}}{d \tau_{B}}=-\frac{1}{\Delta} \frac{\partial P^{X}}{\partial X}
\end{aligned}
$$

where 


$$
\Delta=-\frac{\partial C_{A}}{\partial V_{A}}\left(1+\frac{\partial z_{A}}{\partial X_{A}}\right)\left[\frac{\partial P^{X}}{\partial X}-\frac{\partial C_{B}}{\partial V_{B}}\left(1+\frac{\partial z_{B}}{\partial X_{B}}\right)\right]-\frac{\partial P^{X}}{\partial X} \frac{\partial C_{B}}{\partial V_{B}}\left(1+\frac{\partial z_{B}}{\partial X_{B}}\right)
$$

Using (A.7) for $\mathrm{k}=\mathrm{A}, \mathrm{B}$ it follows:

$$
\left(1+\frac{\partial z_{k}}{\partial X_{k}}\right)=\frac{\frac{\partial P_{k}^{Y}}{\partial Y_{k}}}{\frac{\partial P_{k}^{Y}}{\partial Y_{k}}-\frac{\partial C_{k}}{\partial V_{k}}}>0
$$

which immediately implies $\Delta>0$. Note that (A.11)-(A.14) then imply:

$$
\frac{d X_{A}}{d \tau_{A}}=\frac{\partial X_{A}^{r}}{\partial \tau_{A}}<0, \frac{d X_{A}}{d \tau_{B}}=\frac{\partial X_{A}^{r}}{\partial \tau_{B}}>0, \frac{d X_{A}}{d t_{A}}=\frac{\partial X_{A}^{r}}{\partial t_{A}}>0, \frac{d X_{A}}{d t_{B}}=\frac{\partial X_{A}^{r}}{\partial t_{B}}<0
$$

Moreover, (A.8), (A.11) and (A.12) imply $\left|\frac{\partial X_{A}^{r}}{\partial \tau_{A}}\right|>\left|\frac{\partial X_{A}^{r}}{\partial t_{A}}\right|$.

Finally, to determine the impact of taxes on local demands, note from (A.5)-(A.6) that

$$
\begin{aligned}
& \frac{d Y_{A}}{d t_{A}}=\frac{\partial z_{A}}{\partial X_{A}} \frac{d X_{A}}{d t_{A}}+\frac{\partial z_{A}}{\partial t_{A}} \\
& \frac{d Y_{A}}{d \tau_{A}}=\frac{\partial z_{A}}{\partial X_{A}} \frac{d X_{A}}{d \tau_{A}} \\
& \frac{d Y_{A}}{d t_{B}}=\frac{\partial z_{A}}{\partial X_{A}} \frac{d X_{A}}{d t_{B}} \\
& \frac{d Y_{A}}{d \tau_{B}}=\frac{\partial z_{A}}{\partial X_{A}} \frac{d X_{A}}{d \tau_{B}}
\end{aligned}
$$

so that, using all previous results, it immediately follows:

$$
\frac{d Y_{A}}{d \tau_{A}}=\frac{\partial Y_{A}^{r}}{\partial \tau_{A}}>0, \frac{d Y_{A}}{d \tau_{B}}=\frac{\partial Y_{A}^{r}}{\partial \tau_{B}}<0, \frac{d Y_{A}}{d t_{A}}=\frac{\partial Y_{A}^{r}}{\partial t_{A}}<0, \frac{d Y_{A}}{d t_{B}}=\frac{\partial Y_{A}^{r}}{\partial t_{B}}>0
$$

For the reduced form demand functions for country B, the signs of the different tax effects are determined completely analogously. 


\section{Optimal tax rules}

The first-order conditions to optimisation problem (8) can be written, using the fact that in equilibrium generalised cost equals generalised price, as:

$$
\begin{aligned}
& \left(t_{A}-Y_{A} \frac{\partial C_{A}}{\partial V_{A}}\right) \frac{\partial Y_{A}^{r}}{\partial t_{A}}+\left(\tau_{A}-Y_{A} \frac{\partial C_{A}}{\partial V_{A}}\right) \frac{\partial X_{A}^{r}}{\partial t_{A}}=0 \\
& \left(t_{A}-Y_{A} \frac{\partial C_{A}}{\partial V_{A}}\right) \frac{\partial Y_{A}^{r}}{\partial \tau_{A}}+\left(\tau_{A}-Y_{A} \frac{\partial C_{A}}{\partial V_{A}}\right) \frac{\partial X_{A}^{r}}{\partial \tau_{A}}+X_{A}=0
\end{aligned}
$$

Writing the system in matrix notation and solving by Cramers' rule yields the tax rule for local traffic as follows:

$$
t_{A}=\frac{1}{D}\left\{Y_{A} \frac{\partial C_{A}}{\partial V_{A}}[D]+X_{A} \frac{\partial X_{A}^{r}}{\partial t_{A}}\right\}
$$

where

$$
D=\frac{\partial Y_{A}^{r}}{\partial t_{A}} \frac{\partial X_{A}^{r}}{\partial \tau_{A}}-\frac{\partial Y_{A}^{r}}{\partial \tau_{A}} \frac{\partial X_{A}^{r}}{\partial t_{A}}=\frac{\partial z_{A}}{\partial t_{A}} \frac{\partial X_{A}^{r}}{\partial \tau_{A}}
$$

The last equality follows from the definition of the various demand effects derived before. Substituting D in (A.17) and slightly manipulating the result immediately gives the local tax:

$$
t_{A}=\left(Y_{A}+X_{A}\right) \frac{\partial C_{A}}{\partial V_{A}}=L M E C_{A}+X_{A} \frac{\partial C_{A}}{\partial V_{A}}
$$

Using similar procedures we find for the transit tax

$$
\tau_{A}=Y_{A} \frac{\partial C_{A}}{\partial V_{A}}-X_{A}\left[\frac{\frac{\partial Y_{A}^{r}}{\partial t_{A}}}{\frac{\partial z_{A}}{\partial t_{A}} \frac{\partial X_{A}^{r}}{\partial \tau_{A}}}\right]
$$

Finally, comparison of (A.18) and (A.19) implies that the tax on transit exceeds the tax on local transport, implying tax exporting behaviour. To see this, note that we have:

$$
\tau_{A}-t_{A}=-X_{A}\left[\frac{\partial C_{A}}{\partial V_{A}}+\frac{\frac{\partial Y_{A}^{r}}{\partial t_{A}}}{\frac{\partial z_{A}}{\partial t_{A}} \frac{\partial X_{A}^{r}}{\partial \tau_{A}}}\right]
$$


Substituting $\frac{\partial Y_{A}^{r}}{\partial t_{A}}=\frac{\partial z_{A}}{\partial X_{A}} \frac{\partial X_{A}^{r}}{\partial t_{A}}+\frac{\partial z_{A}}{\partial t_{A}}$, using $\frac{\partial z_{A}}{\partial X_{A}}=\frac{\partial C_{A}}{\partial V_{A}} \frac{\partial z_{A}}{\partial t_{A}}$ (see (A.7)-(A.8)) and rearranging yields

$$
\tau_{A}-t_{A}=-X_{A}\left[\frac{1+\frac{\partial C_{A}}{\partial V_{A}}\left[\frac{\partial X_{A}^{r}}{\partial \tau_{A}}+\frac{\partial X_{A}^{r}}{\partial t_{A}}\right]}{\frac{\partial X_{A}^{r}}{\partial \tau_{A}}}\right]
$$

Using (A.11)-(A.12) and explicitly substituting $\Delta$ then yields, after some manipulation:

$$
\tau_{A}-t_{A}=X_{A}\left[\frac{\frac{\partial P^{X}}{\partial X} \frac{\partial C_{B}}{\partial V_{B}}\left[1+\frac{\partial z_{B}}{\partial X_{B}}\right]}{\frac{\partial P^{X}}{\partial X}-\frac{\partial C_{B}}{\partial V_{B}}\left[1+\frac{\partial z_{B}}{\partial X_{B}}\right]}\right]>0
$$

\section{Appendix 2: Detailed analysis of the case of uniform tolls}

$\underline{\text { Reduced-form demand system }}$

Using similar developments as in the differentiated tolling case we immediately obtain (the definition of $\Delta>0$ is unchanged):

$$
\begin{gathered}
\frac{d X_{A}}{d \theta_{A}}=\frac{1}{\Delta}\left\{\left(1+\frac{\partial C_{A}}{\partial V_{A}} \frac{\partial z_{A}}{\partial \theta_{A}}\right)\left[\frac{\partial P^{X}}{\partial X}-\frac{\partial C_{B}}{\partial V_{B}}\left(1+\frac{\partial z_{B}}{\partial X_{B}}\right)\right]\right\}<0 \\
\frac{d X_{A}}{d \theta_{B}}=\frac{-1}{\Delta}\left[\frac{\partial P^{X}}{\partial X}\left(1+\frac{\partial C_{B}}{\partial V_{B}} \frac{\partial z_{B}}{\partial X_{B}}\right)\right]>0
\end{gathered}
$$

Furthermore, analogous procedures as in the case of differentiated taxes immediately yield:

$$
\frac{d Y_{A}}{d \theta_{A}}<0, \frac{d Y_{A}}{d \theta_{B}}<0
$$

$\underline{\text { Optimal tax rules }}$

The first-order condition to the problem

$$
\operatorname{Max}_{\theta_{A}} W_{A}=\int_{0}^{Y_{A}}\left(P_{A}^{Y}\left(Y_{A}\right)\right) d Y_{A}-g_{A}^{Y} * Y_{A}+\theta_{A}\left(Y_{A}+X_{A}\right),
$$


can be written as:

$$
P_{A}^{Y} \frac{\partial Y_{A}^{r}}{\partial \theta_{A}}-g_{A}^{Y} \frac{\partial Y_{A}^{r}}{\partial \theta_{A}}-Y_{A}\left[\frac{\partial C_{A}}{\partial V_{A}}\left(\frac{\partial Y_{A}^{r}}{\partial \theta_{A}}+\frac{\partial X_{A}^{r}}{\partial \theta_{A}}\right)+1\right]+\theta_{A}\left(\frac{\partial Y_{A}^{r}}{\partial \theta_{A}}+\frac{\partial Y_{A}^{r}}{\partial \theta_{A}}\right)+\left(Y_{A}^{r}+X_{A}^{r}\right)=0
$$

Simplifying and solving for the tax yields:

$$
\theta_{A}=Y_{A} \frac{\partial C_{A}}{\partial V_{A}}-\frac{X_{A}^{r}}{\frac{\partial Y_{A}^{r}}{\partial \theta_{A}}+\frac{\partial X_{A}^{r}}{\partial \theta_{A}}}
$$

\section{Appendix 3: Detailed analysis of the case 'local tolls only'}

\section{$\underline{\text { Reduced-form demand system }}$}

The derivatives of the reduced-form demand functions with respect to the local tolls are easily shown to be identical to those for the differentiated tolling case. Indeed, the only difference is that the transit toll is set to zero.

\section{Optimal tax rules}

The first-order condition to the problem

$$
\operatorname{Max}_{t_{A}} W_{A}=\int_{0}^{Y_{A}}\left(P_{A}^{Y}\left(Y_{A}\right)\right) d Y_{A}-g_{A}^{Y} * Y_{A}+t_{A} Y_{A}
$$

immediately yields, after simple manipulation:

$$
t_{A} \frac{\partial Y_{A}^{r}}{\partial t_{A}}-\left(Y_{A} \frac{\partial C_{A}}{\partial V_{A}}\right)\left(\frac{\partial Y_{A}^{r}}{\partial t_{A}}+\frac{\partial X_{A}^{r}}{\partial t_{A}}\right)=0
$$

Solving for the optimal local toll leads to:

$$
t_{A}=Y_{A} \frac{\partial C_{A}}{\partial V_{A}}\left[1+\frac{\frac{\partial X_{A}^{r}}{\partial t_{A}}}{\frac{\partial Y_{A}^{r}}{\partial t_{A}}}\right]
$$


Importantly, the term between square brackets can be shown to be positive (and smaller than one), implying the optimal tax is between zero and the local marginal external cost. To see this, remember that the derivatives of the reduced-form demand functions are given by the same expressions A.11 and A.13 as for the differentiated tolling case. Then substitute the definition of $\Delta$ and use A.7-A.8 to obtain, after straightforward manipulation:

$$
1+\frac{\frac{\partial X_{A}^{r}}{\partial t_{A}}}{\frac{\partial Y_{A}^{r}}{\partial t_{A}}}=\frac{M_{1}}{\left(\frac{\partial C_{A}}{\partial V_{A}}-\frac{\partial P_{Y}^{A}}{\partial Y_{A}}\right)\left\{\frac{\partial C_{A}}{\partial V_{A}} \frac{\partial z_{A}}{\partial t_{A}}\left[M_{2}\right]\right\}+M_{1}}
$$

where

$$
\begin{aligned}
& M_{1}=-\frac{\partial P^{X}}{\partial X} \frac{\partial C_{B}}{\partial V_{B}}\left[1+\frac{\partial z_{B}}{\partial X_{B}}\right]>0 \\
& M_{2}=\frac{\partial P^{X}}{\partial X}-\frac{\partial C_{B}}{\partial V_{B}}\left[1+\frac{\partial z_{B}}{\partial X_{B}}\right]<0
\end{aligned}
$$

It immediately follows that the both the numerator and the denominator of the right-hand side of A.22 are positive. .

\section{Appendix 4: Details on the reaction functions and the Nash equilibria}

\section{$\underline{1 .}$ The case of differentiated tolls}

We consecutively derive the reduced-form demands, the reaction functions, and the Nash equilibrium. To get the reduced-form demands, we follow the procedure outlined in Appendix 1 for the linear demand and cost functions given in the main body of the paper. The demands for local transport conditional on transit and the local tax are given by

$$
\begin{aligned}
& Y_{A}=z_{0}^{A}+z_{1}^{A} X_{A}+z_{2}^{A} t_{A} \\
& Y_{B}=z_{0}^{B}+z_{1}^{B} X_{B}+z_{2}^{B} t_{B}
\end{aligned}
$$

where 


$$
\begin{aligned}
& z_{0}^{A}=\frac{c_{A}-\alpha_{A}}{d_{A}+\beta_{A}}, z_{1}^{A}=-\frac{\beta_{A}}{d_{A}+\beta_{A}}, z_{2}^{A}=-\frac{1}{d_{A}+\beta_{A}} \\
& z_{0}^{B}=\frac{c_{B}-\alpha_{B}}{d_{B}+\beta_{B}}, z_{1}^{B}=-\frac{\beta_{B}}{d_{B}+\beta_{B}}, z_{2}^{B}=-\frac{1}{d_{B}+\beta_{B}}
\end{aligned}
$$

Substituting these functions in the Wardrop equilibrium conditions yields, after some manipulations, the reduced-form demands for transit transport. We find:

$$
\begin{aligned}
& X_{A}^{r}=\gamma_{0}^{A}+\gamma_{1}^{A} \tau_{A}+\gamma_{2}^{A} \tau_{B}+\gamma_{3}^{A} t_{A}+\gamma_{4}^{A} t_{B} \\
& X_{B}^{r}=\gamma_{0}^{B}+\gamma_{1}^{B} \tau_{B}+\gamma_{2}^{B} \tau_{A}+\gamma_{3}^{B} t_{B}+\gamma_{4}^{B} t_{A}
\end{aligned}
$$

where the coefficients are given by

$$
\begin{array}{ll}
\gamma_{0}^{A}=\frac{b^{2}\left(z_{0}^{B}-z_{0}^{A}\right)+\left(a-b z_{0}^{A}\right) T^{B}}{N} & \gamma_{0}^{B}=\frac{b^{2}\left(z_{0}^{A}-z_{0}^{B}\right)+\left(a-b z_{0}^{B}\right) T^{A}}{N} \\
\gamma_{1}^{A}=-\frac{\left[b+T^{B}\right]}{N} & \gamma_{1}^{B}=-\frac{\left[b+T^{A}\right]}{N} \\
\gamma_{2}^{A}=\frac{b}{N} & \gamma_{2}^{B}=\frac{b}{N} \\
\gamma_{3}^{A}=-\left\{\frac{z_{1}^{A}\left[b+T^{B}\right]}{N}\right\} & \gamma_{3}^{B}=-\left\{\frac{z_{1}^{B}\left[b+T^{A}\right]}{N}\right\} \\
\gamma_{4}^{A}=\frac{b z_{1}^{B}}{N} & \gamma_{4}^{B}=\frac{b z_{1}^{A}}{N}
\end{array}
$$

In these expressions $N=b T^{A}+b T^{B}+T^{A} T^{B}$, and $T^{A}=\beta_{A}\left(1+z_{1}^{A}\right), \quad T^{B}=\beta_{B}\left(1+z_{1}^{B}\right)$. Since, using (A.24)-(A.25), the $T^{i}$ are easily shown to be positive, it immediately follows that $\mathrm{N}>0$. Therefore, we have

$$
\begin{aligned}
& \gamma_{1}^{A}<0, \gamma_{2}^{A}>0, \gamma_{3}^{A}>0, \gamma_{4}^{A}<0 . \\
& \gamma_{1}^{B}<0, \gamma_{2}^{B}>0, \gamma_{3}^{B}>0, \gamma_{4}^{B}<0 .
\end{aligned}
$$

Note that the reduced form demand functions have a straightforward structure. More precisely, observe that the coefficients of the local and the transit taxes are directly related in the following simple manner $(\mathrm{i}=\mathrm{A}, \mathrm{B})$ : 


$$
\begin{aligned}
& \gamma_{3}^{i}=z_{1}^{i} \gamma_{1}^{i} \\
& \gamma_{4}^{i}=z_{1}^{i} \gamma_{2}^{i}
\end{aligned}
$$

Moreover, using (A.24)-(A.25) it immediately follows that $-1<z_{1}^{i}<0$ so that:

$$
\begin{aligned}
& \left|\gamma_{3}^{i}\right|<\left|\gamma_{1}^{i}\right| \\
& \left|\gamma_{4}^{i}\right|<\left|\gamma_{2}^{i}\right|
\end{aligned}
$$

Finally, note that reduced form demands for local traffic are obtained by inserting the demands for transit (equations (A.26)-(A.27)) into system (A.23).

The reaction functions are derived as follows. Using the linear demand and cost functions in the optimal tax rules for country A derived in Appendix 1, we find after some algebra:

$$
\begin{aligned}
& t_{A}=\beta_{A}\left(Y_{A}+X_{A}\right) \\
& \tau_{A}=\beta_{A} Y_{A}+\rho_{A} X_{A}
\end{aligned}
$$

where

$$
\rho_{A}=\beta_{A}+\frac{b T^{B}}{b+T^{B}}
$$

Substituting (A.23), (A.26) and (A.27) into (A.31)-(A.32) and solving for the tax rates in A as sole functions of the two tax rates in B yields, again after some algebra,

$$
\begin{aligned}
& \tau_{A}=c_{A}^{\tau}-\left(\frac{1}{2} \frac{\gamma_{2}^{A}}{\gamma_{1}^{A}}\right) \tau_{B}-\left(\frac{1}{2} \frac{\gamma_{4}^{A}}{\gamma_{1}^{A}}\right) t_{B} \\
& t_{A}=c_{A}^{t}+\left(\frac{1}{2} \frac{\gamma_{2}^{A}}{\gamma_{1}^{A}} K^{A}\right) \tau_{B}+\left(\frac{1}{2} \frac{\gamma_{4}^{A}}{\gamma_{1}^{A}} K^{A}\right) t_{B}
\end{aligned}
$$

where all coefficients have been defined before, except

$$
\begin{aligned}
c_{A}^{\tau} & =\frac{1}{2}\left(\beta_{A} z_{0}^{A}-\frac{\gamma_{0}^{A}}{\gamma_{1}^{A}}\right) \\
c_{A}^{t} & =\left[\beta_{A} z_{0}^{A}+\frac{1}{2} T^{A}\left(\beta_{A} z_{0}^{A} \gamma_{1}^{A}+\gamma_{0}^{A}\right)\right] \frac{K^{A}}{T^{A} \gamma_{1}^{A}} \\
K^{A} & =\frac{T^{A} \gamma_{1}^{A}}{1-z_{1}^{A}\left(1+T^{A} \gamma_{1}^{A}\right)}
\end{aligned}
$$


Moreover, for purposes of the interpretation it is useful to note that $-1<K^{A}<0$. This is easily seen to be the case as follows. First,

$$
T^{A} \gamma_{1}^{A}=-\frac{T^{A}\left(b+T^{B}\right)}{N}=-\frac{T^{A}\left(b+T^{B}\right)}{b T^{A}+b T^{B}+T^{A} T^{B}}
$$

which implies $-1<T^{A} \gamma_{1}^{A}<0$. This in turn implies $-1<K^{A}<0$.

Importantly, since the tax competition problem considered in this section is a game with four tax rates, it is not obvious to prove the existence and uniqueness of Nash equilibrium in this general setting. Fortunately, the linear structure of the problem allows us to reduce the fourdimension game into a policy game in two dimensions; moreover, existence and uniqueness then immediately follow. To see this, consider the structure of the reaction functions (A.33) and note that the local and transit tax rates of each country can be written as a function of the same linear combination of the tax rates of the other country. Specifically, define:

$$
\begin{aligned}
& \pi_{A}=\tau_{A}+z_{B}^{1} t_{A} \\
& \pi_{B}=\tau_{B}+z_{A}^{1} t_{B}
\end{aligned}
$$

Substituting this result in (A.33) we obtain:

$$
\begin{aligned}
\tau_{A} & =c_{A}^{\tau}-r^{A} \pi_{B} \\
t_{A} & =c_{A}^{t}-r^{A} K^{A} \pi_{B}
\end{aligned}
$$

where $r^{A}=\frac{1}{2} \frac{\gamma_{2}^{A}}{\gamma_{1}^{A}}$. Similar expressions result for region B. Noting that only positive $\pi_{i}$ make economic sense, we can then reformulate (A.33) and its equivalent for B as follows:

$$
\begin{aligned}
& \pi_{A}=s^{A}+p^{A} \pi_{B} \\
& \pi_{B}=s^{B}+p^{B} \pi_{A}
\end{aligned}
$$

where

$$
\begin{aligned}
& s^{A}=c_{A}^{\tau}+z_{1}^{B} c_{A}^{t} \\
& s^{B}=c_{B}^{\tau}+z_{1}^{A} c_{B}^{t} \\
& p^{A}=-r^{A}\left(1+z_{1}^{B} K^{A}\right) \\
& p^{B}=-r^{B}\left(1+z_{1}^{A} K^{B}\right)
\end{aligned}
$$


Simple algebra, using the definitions given before and realising that $-1<K^{i}<0$, then shows that the reaction functions have a positive intercept, are upward sloping, and have a slope less than one. Finally, note that solving the reaction functions for the original four tax rates yields the Nash equilibrium in function of the various coefficients that describe cost and demand responses. The solution is however not transparent and does not yield extra insights.

\section{$\underline{\text { 2. The case of uniform tolls }}$}

We follow the same steps and use the same definitions as in the previous case. The reducedform demands for local transport conditional on transit and the local tax are given by

$$
\begin{aligned}
& Y_{A}=z_{0}^{A}+z_{1}^{A} X_{A}+z_{2}^{A} \theta_{A} \\
& Y_{B}=z_{0}^{B}+z_{1}^{B} X_{B}+z_{2}^{B} \theta_{B}
\end{aligned}
$$

The reduced-form demand functions for transit are now the following:

$$
\begin{aligned}
& X_{A}^{r}=\gamma_{0}^{A}+\left(\gamma_{1}^{A}+\gamma_{3}^{A}\right) \theta_{A}+\left(\gamma_{2}^{A}+\gamma_{4}^{A}\right) \theta_{B} \\
& X_{B}^{r}=\gamma_{0}^{B}+\left(\gamma_{1}^{B}+\gamma_{3}^{B}\right) \theta_{B}+\left(\gamma_{2}^{B}+\gamma_{4}^{B}\right) \theta_{A}
\end{aligned}
$$

where the coefficients are defined as above.

To obtain the reaction function for region A, use

$$
\begin{aligned}
& \frac{\partial Y_{A}^{r}}{\partial \theta_{A}}=z_{2}^{A}+z_{1}^{A}\left(\gamma_{1}^{A}+\gamma_{3}^{A}\right)<0 \\
& \frac{\partial X_{A}^{r}}{\partial \theta_{A}}=\gamma_{1}^{A}+\gamma_{3}^{A}<0
\end{aligned}
$$

in the optimal tax rule derived in Appendix 2:

$$
\theta_{A}=Y_{A} \frac{\partial C_{A}}{\partial V_{A}}-\frac{X_{A}^{r}}{\frac{\partial Y_{A}^{r}}{\partial \theta_{A}}+\frac{\partial X_{A}^{r}}{\partial \theta_{A}}}
$$

Solving explicitly for the optimal tax, we find the reaction function:

$$
\theta_{A}=\frac{c_{2}^{t u A}}{c_{1}^{t u A}}+\frac{c_{3}^{t u A}}{c_{1}^{t u A}} \theta_{B}
$$


where

$$
\begin{gathered}
c_{1}^{t u A}=1-z_{1}^{A}-\left(\beta_{A} z_{1}^{A}+\eta_{A}\right)\left(\gamma_{1}^{A}+\gamma_{3}^{A}\right) \\
c_{2}^{t u A}=\left(\beta_{A} z_{1}^{A}+\eta_{A}\right) \gamma_{0}^{A}+\beta_{A} z_{0}^{A} \\
c_{3}^{t u A}=\left(\beta_{A} z_{1}^{A}+\eta_{A}\right)\left(\gamma_{2}^{A}+\gamma_{4}^{A}\right)
\end{gathered}
$$

and

$$
\eta_{A}=-\frac{1}{\left(1+z_{1}^{A}\right)\left(\gamma_{1}^{A}+\gamma_{3}^{A}\right)+z_{2}^{A}}>0
$$

Tedious algebra shows that $\left(\beta_{A} z_{1}^{A}+\eta_{A}\right)>0$ so that $c_{3}^{\text {tuA }}>0, c_{1}^{\text {tuA }}>0$ : the reaction functions are upward sloping. Moreover, a Nash equilibrium indeed exists. This requires the condition:

$$
\frac{c_{3}^{t u A}}{c_{1}^{t u A}} \frac{c_{3}^{t u B}}{c_{1}^{t u B}}<1
$$

which, using straightforward algebra, can easily be shown to hold.

\section{Local tolls only}

Again we follow the same steps and use the same definitions as in the section for the differentiated tolls. The demands for local transport conditional on transit and the local tax are given by

$$
\begin{aligned}
& Y_{A}=z_{0}^{A}+z_{1}^{A} X_{A}+z_{2}^{A} t_{A} \\
& Y_{B}=z_{0}^{B}+z_{1}^{B} X_{B}+z_{2}^{B} t_{B}
\end{aligned}
$$

Reduced-form demands for transit are:

$$
\begin{aligned}
& X_{A}^{r}=\gamma_{0}^{A}+\gamma_{3}^{A} t_{A}+\gamma_{4}^{A} t_{B} \\
& X_{B}^{r}=\gamma_{0}^{B}+\gamma_{3}^{B} t_{B}+\gamma_{4}^{B} t_{A}
\end{aligned}
$$

To get the reaction function for country A, use the above specifications in the optimal tax rule

$$
t_{A}=Y_{A} \frac{\partial C_{A}}{\partial V_{A}}\left(1+\frac{\frac{\partial Y_{A}^{r}}{\partial t_{A}}}{\frac{\partial X_{A}^{r}}{\partial t_{A}}}\right)
$$


The result turns out to be:

$$
t_{A}=\frac{c_{2}^{t l A}}{c_{1}^{t l A}}+\frac{c_{3}^{t l A}}{c_{1}^{t l A}} t_{B}
$$

where

$$
\begin{gathered}
c_{1}^{t l A}=1-\beta_{A} \delta_{A}\left(z_{2}^{A}+z_{1}^{A} \gamma_{3}^{A}\right) \\
c_{2}^{t l A}=\beta_{A} \delta_{A}\left(z_{0}^{A}+z_{1}^{A} \gamma_{0}^{A}\right) \\
c_{3}^{t l A}=\beta_{A} \delta_{A} z_{1}^{A} \gamma_{4}^{A}
\end{gathered}
$$

Again, simple but long algebra shows that the slope of the reaction function is positive; moreover, assuming all types of transport exist in the equilibrium, the existence of a Nash equilibrium can be shown. This follows because one shows that $\frac{c_{3}^{t l A}}{c_{1}^{t l A}} \frac{c_{3}^{t l B}}{c_{1}^{t l B}}<1$. 
The Center for Economic Studies (CES) is the research division of the Department of Economics of the Katholieke Universiteit Leuven. The CES research department employs some 100 people. The division Energy, Transport \& Environment (ETE) currently consists of about 15 full time researchers. The general aim of ETE is to apply state of the art economic theory to current policy issues at the Flemish, Belgian and European level. An important asset of ETE is its extensive portfolio of numerical partial and general equilibrium models for the assessment of transport, energy and environmental policies.

\section{ETE WORKING PAPER SERIES 2003}

$n^{\circ} 2003-09$

$n^{\circ} 2003-08$

$n^{\circ} 2003-07$

$n^{\circ} 2003-06$

$n^{\circ} 2003-05$

$n^{\circ} 2003-04$

$n^{\circ} 2003-03$

$n^{\circ} 2003-02$

$n^{\circ} 2003-01$
B.De Borger, S.Proost, K.Van Dender, Congestion And Tax Competition In A Parallel Network

Pepermans G., Driesen J., Haeseldonckx D., D'haeseleer W. and Belmans R. (2003), Distributed generation: definition, benefits and issues

Moons E., The development and application of economic valuation techniques and their use in environmental policy - A survey

Muys B., Deckmyn G., Moons E., Quijano J.G., Proost S. and Ceulemans R. (2003), An integrated decision support tool for the prediction and evaluation of efficiency, environmental impact and total social cost of forestry projects in the framework of the Kyoto protocol

Proost, S. and Van Regemorter, D. (2003), Climate change policy in European countries and its effects on industry

Willems, B. (2003), Should an incumbent generator be allowed to buy import transmission capacity?

Rousseau, S. and Billiet, C.M. (2003), Using emission standards under incomplete compliance

Calthrop, E., De Borger, B. and Proost S. (2003), Tax reform for dirty intermediate goods: theory and an application to the taxation of freight transport

Pepermans, G. (2003), Simulating the restructuring of the Flemish electricity distribution sector

\section{ETE WORKING PAPER SERIES 2002}

Willems, B. (2002), Barring consumers from the electricity network might improve welfare

Mayeres, I. And Proost, S. (2002), Reforming transport pricing: an economist's perspective on equity, efficiency and acceptability 
$n^{\circ} 2002-10$

$n^{\circ} 2002-09$

$n^{\circ} 2002-08$

$n^{\circ} 2002-07$

$n^{\circ} 2002-06$

$n^{\circ} 2002-05$

$n^{\circ} 2002-04$

$\mathrm{n}^{\circ} 2002-03$

$n^{\circ} 2002-02$

$n^{\circ} 2002-01$
Franckx, L. and Kampas, A. (2002), A Note on "The Choice between Emission Taxes and Output Taxes under Imperfect Monitoring"

Eyckmans, J. (2002) International Environment Agreements And The Case Of Global Warming

Calthrop, E. Proost, S. (2002) Environmental Pricing in Transport Chapter for Handbook 4: Transport and the Environment

De Borger, B. and Van Dender, K. (2002), Transport tax reform, commuting and endogenous values of time

Franckx, L. and d'Amato, A. (2002), Multiple-task common agency with one fully-informed principal: implications for public policy

Moons, E. (2002), Cost- benefit analysis of the location of new forest land

Rousseau, S. and Proost, S. (2002), The Cost Effectiveness of Environmental Policy Instruments in the Presence of Imperfect Compliance

Calthrop, E. (2002), Evaluating on-street parking policy

Calthrop, E., and Proost, S. (2002), Regulating on-street parking

Franckx, L. (2002), Penalty and crime with lumpy choices: some further considerations 


\section{ETE WORKING PAPER SERIES 2001}

$N^{\circ} 2001-26$

$n^{\circ} 2001-25$

$n^{\circ} 2001-24$

$n^{\circ} 2001-23$

$n^{\circ} 2001-22$

$n^{\circ} 2001-21$

$n^{\circ} 2001-20$

$n^{\circ} 2001-19$

$n^{\circ} 2001-18$

$n^{\circ} 2001-17$

$n^{\circ} 2001-16$

$n^{\circ} 2001-15$

$n^{\circ} 2001-14$

$n^{\circ} 2001-13$

$n^{\circ} 2001-12$

$n^{\circ} 2001-11$

$n^{\circ} 2001-10$

$n^{\circ} 2001-09$

$n^{\circ} 2001-08$

$\mathrm{n}^{\circ} 2001-07$

$n^{\circ} 2001-06$

Rousseau, S. (2001), Effluent trading to improve water quality: what do we know today?

Degraeve, Z., Proost, S. and Wuyts, G. (2001), Cost-efficiency methodology for the selection of new car emission standards in Europe

Bigano, A. (2001), Environmental Dumping, Transboundary Pollution And Asymmetric Information - Some Insights For The Environmental Regulation Of The European Electricity Market

Mayeres, I., and Proost, S. (2001), Can we use transport accounts for pricing policy and distributional analysis?

Moons, E., Loomis, J., Proost, S., Eggermont, K. and Hermy, M. (2001), Travel cost and time measurement in travel cost models

Calthrop, E. (2001), Pricing a stock-constrained congestible facility

S. Proost, K. Van Dender, C. Courcelle, B. De Borger, J. Peirson, D. Sharp, R. Vickerman, E. Gibbons, M. O'Mahony, Q. Heaney, J. Van den Bergh, E. Verhoef (2001), How large is the gap between present and efficient transport prices in Europe?

Van Dender, K., and Proost, S. (2001), Optimal urban transport pricing with congestion and economies of density

Eyckmans, J., Van Regemorter, D., and van Steenberghe, V. (2001), Is Kyoto fatally flawed? An analysis with MacGEM

Van Dender, K. (2001), Transport taxes with multiple trip purposes

Proost, S., and Van Regemorter, D. (2001), Interaction between Local Air Pollution and Global Warming Policy and its Policy Implications

Franckx, L. (2001), Environmental enforcement with endogenous ambient monitoring

Mayeres, I. (2001), Equity and transport policy reform

Calthrop, E. (2001), On subsidising auto-commuting

Franckx, L. (2001), Ambient environmental inspections in repeated enforcement games

Pan, H. (2001), The economics of Kyoto flexible mechanisms: a survey

Calthrop, E. (2001), When consumers can decide not to pay a tax: enforicing and pricing urban on-street parking space

Franckx, L. (2001), Ambient environmental inspections eliminate the need for marginal deterrence

Franckx, L. (2001), Optimal fines for environmental noncompliance under a decentralized enforcement policy

Franckx, L. (2001), Reputation effects in regulatory enforcement

Franckx, L. (2001), Ambient inspections in environmental enforcement: an extension 
$n^{\circ} 2001-05$

$n^{\circ} 2001-04$

$n^{\circ} 2001-03$

$n^{\circ} 2001-02$

$n^{\circ} 2001-01$
Eyckmans, J., and Cornillie, J. (2001), Supplementarity in the European carbon emission market

Franckx, L. (2001), Ambient environmental inspections followed by sequentional firm inspections

Eyckmans J. (2001), On the farsighted stability of the Kyoto Protocol

Van Dender, K. (2001), Pricing transport networks with fixed residential location

Rousseau, S. and Proost, S. (2001), The relative efficiency of environmental policy instruments in a second-best setting with costly monitoring and enforcement (also available as CES Discussion Paper 01.04) 


\section{ETE WORKING PAPER SERIES 2000}

$n^{\circ} 2000-09$

$n^{\circ} 2000-08$

$n^{\circ} 2000-07$

$n^{\circ} 2000-06$

$n^{\circ} 2000-05$

$n^{\circ} 2000-04$

$n^{\circ} 2000-03$

$n^{\circ} 2000-02$

$n^{\circ} 2000-01$

Proost, S., and Van Regemorter, D. (2000), How to achieve the Kyoto Target in Belgium - modelling methodology and some results

Eyckmans J. and Bertrand, C. (2000), Integrated assessment of carbon and sulphur emissions, simulations with the CLIMNEG model

Pepermans G., and Proost, S. (2000), Stranded costs in the electricity sector

Calthrop, E., and Proost, S. (2000), Regulating urban parking space: the choice between meter fees and time restrictions (also available as CES Discussion Paper 00.21)

Mayeres, I., and Proost, S. (2000), Should diesel cars in Europe be discouraged? (also available as CES Discussion Paper 00.18)

Willems, B. (2000), Cournot Competition in the Electricity Market with Transmission Constraints (also available as CES Discussion Paper 00.24)

Pepermans, G., and Proost, S. (2000), The Liberalisation of the Energy Sector in the European Union

Eyckmans, J., and Cornillie, J. (2000), Efficiency and Equity of the EU Burden Sharing Agreement

Bigano, A. (2000), Environmental Regulation for the Liberalised European Electricity Sector. Towards a Numerical Approach 